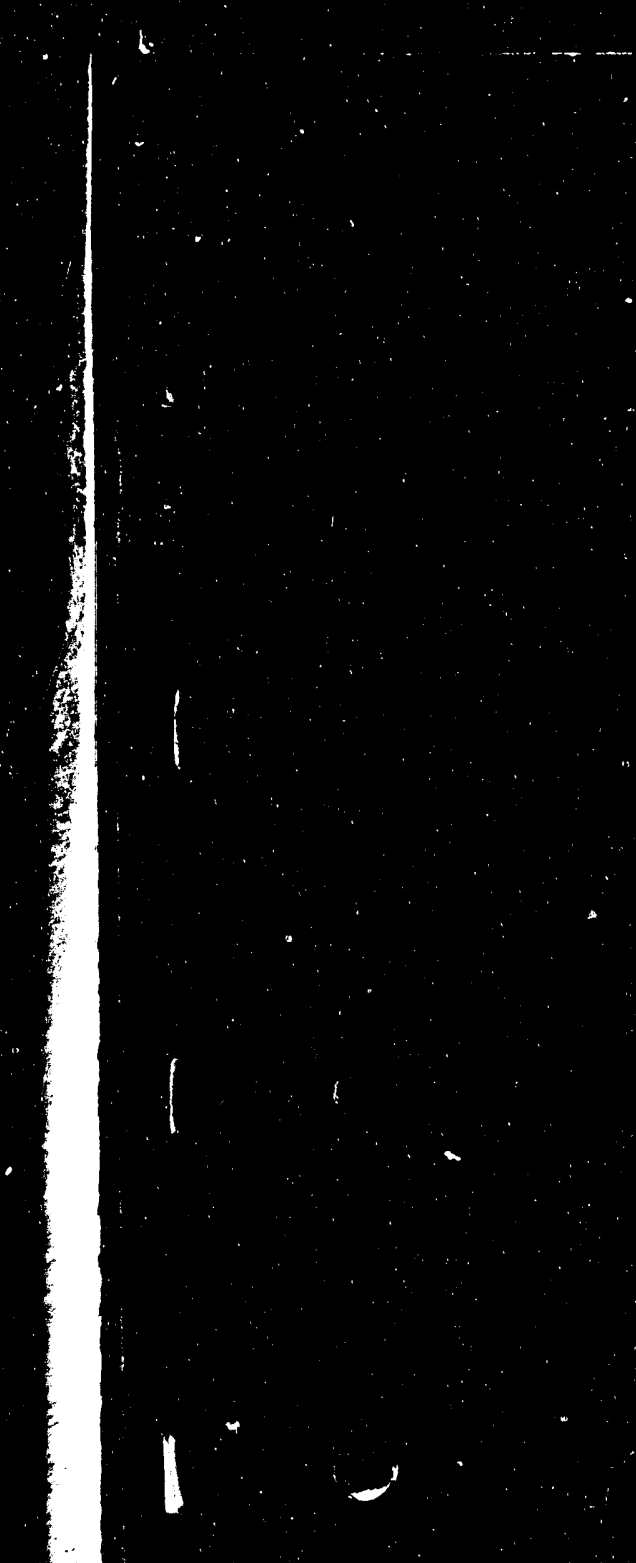

$\therefore$

$10 F 1$ 


\title{
100 Area Excavation Treatability Test Plan
}

\author{
Date Published \\ August 1993
}

\section{DISCLAIMER}

This report was prepared as an account of work sponsored by an agency of the United States Government. Neither the United States Government nor any agency thereof, nor any of their employees, makes any warranty, express or implied, or assumes any legal liability or responsibility for the accuracy, completeness, or usefulness of any information, apparatus, product, or process disclosed, or represents that its use would not infringe privately owned rights. Reference herein to any specific commercial product, process, or service by trade name, trademark. manufacturer, or otherwise does not necessarily constitute or imply its endorsement, recommendation, or favoring by the United States Government or any agency thereof. The views and opinions of authors expressed herein do not necessarily state or reflect those of the United States Government or any agency thereof.

?.

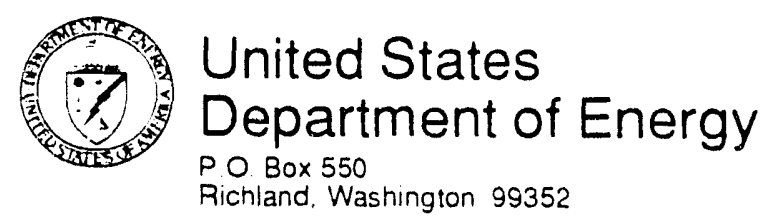

Approved tor Public Release 
DQE/RL-93-04, Rev. 1

\section{ACRONYMS}

$\begin{array}{ll}\text { ALARA } & \text { as low as reasonable achievable } \\ \text { ARAR } & \text { applicable or relevant and appropriate requirement } \\ \text { CFR } & \text { Code of Federal Regulations } \\ \text { DOE } & \text { U.S. Department of Energy } \\ \text { DQO } & \text { data quality objective } \\ \text { Ecology } & \text { Washington Department of Ecology } \\ \text { EII } & \text { environmental investigation instruction } \\ \text { EPA } & \text { U.S. Environmental Protection Agency } \\ \text { FS } & \text { feasibility study } \\ \text { IRM } & \text { interim remedial measure } \\ \text { LFI } & \text { limited field investigation } \\ \text { QAPjP } & \text { quality assurance project plan } \\ \text { QA/QC } & \text { quality assurance/quality control } \\ \text { RI/FS } & \text { remedial investigation/feasibility study } \\ \text { Tri-Party } & \text { Hanford Federal Facility Agreement and Consent Order } \\ \quad \text { Agreement } & \\ \text { WHC } & \text { Westinghouse Hanford Company }\end{array}$




\section{CONTENTS}

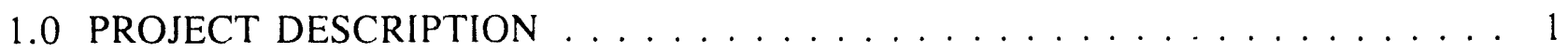

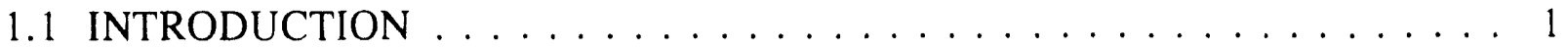

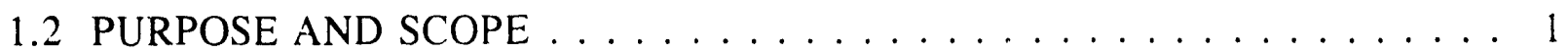

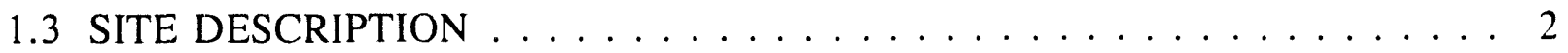

1.3 .1 Site Selection ....................... 2

1.3 .2 Site History . . . . . . . . . . . . . . . . . . . . 3

1.3.3 Nature and Extent of Contamination . . . . . . . . . . . . 3

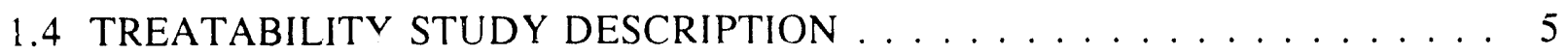

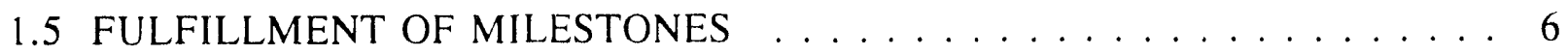

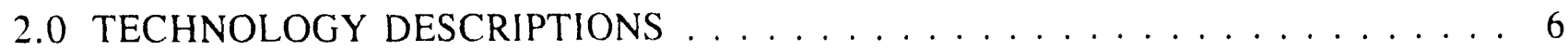

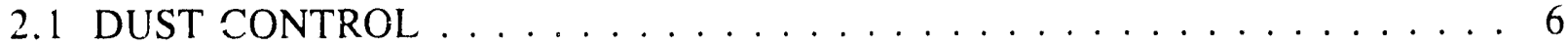

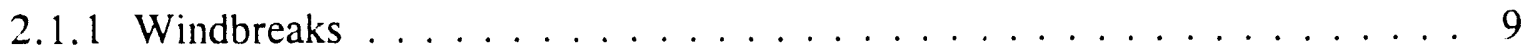

2.1 .2 Water Sprays . . . . . . . . . . . . . . . . . 10

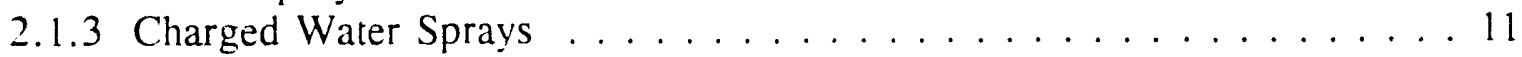

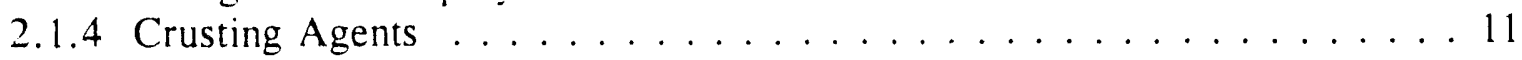

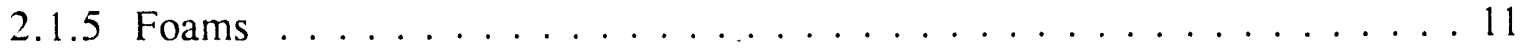

2.2 FIELD/LABORATORY RADIONUCLIDE ANALYSIS CORRELATION _ . 12

2.2 .1 Gamma Radiation . . . . . . . . . . . . . . . 13

2.2 .2 Beta Radiation . . . . . . . . . . . . . . . . . . 17

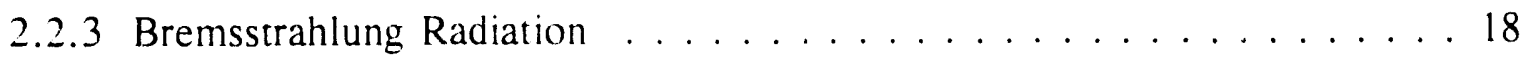

2.2 .4 Alpha Radiation ... . . . . . . . . . . . . . . . . 19

2.2 .5 Neutron Radiation . . . . . . . . . . . . . . . . . . . . . . 19

2.3 FIELD/LABORATORY NONRADIOACTIVE ANALYSIS CORRELATION . 20

3.0 TEST PERFORMANCE AND DATA QUALITY OBJECTIVES . . . . . . . . . 20

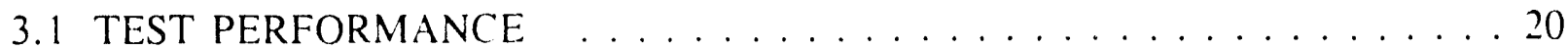

3.1 .1 Dust Control . . . . . . . . . . . . . . . . . 20

3.1.2 Field/Laboratory Radionuclide Analysis Correlation . . . . . . . . 21

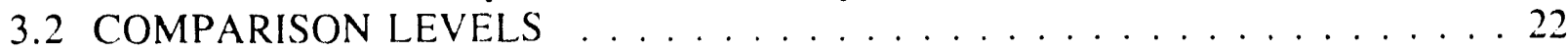

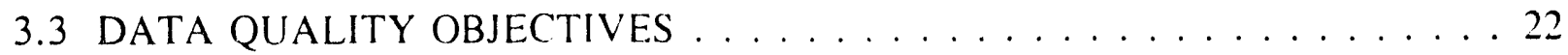

4.0 EXCAVATION TREATABILITY TE.ST EXPERIMENTAL

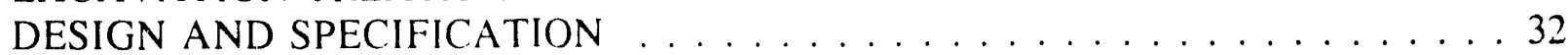

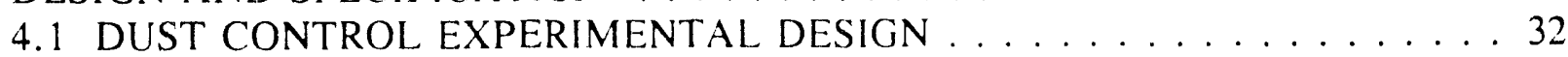

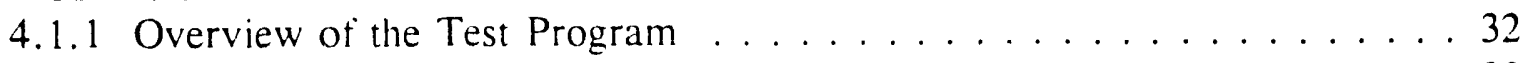

4.1 .2 Site Layout . . . . . . . . . . . . . . . . . 33

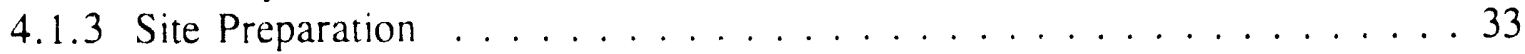

4.1 .4 Test Excavation . . . . . . . . . . . . . . . . . . . . 34

4.1.5 Dust Suppression Test Program . . . . . . . . . . . . . . . . 34

4.1 .6 Backfilling and Compaction . . . . . . . . . . . 37 


\section{CONTENTS (cont)}

4.2 FIELD/LABORATORY RADIONUCLIDE ANALYSIS CORRELATION

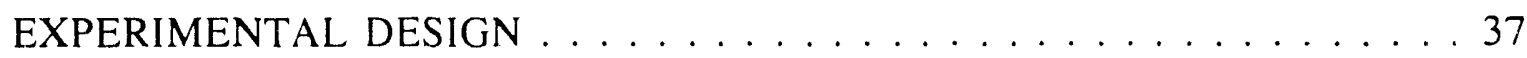

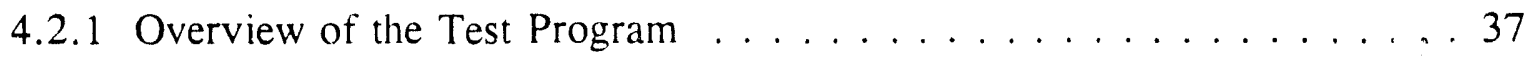

4.2 .2 Gamma Pulse Height Analysis Test . . . . . . . . . . . . . . . 38

4.2 .3 Gross Beta Test . . . . . . . . . . . . . . . . . . 38

4.2.4 Gamma Detection from Transuranic Test . . . . . . . . . . . . . . . 38

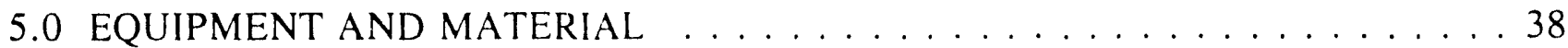

5.1 FIELD/LABORATORY RADIONUCLIDE ANALYSIS CORRELATION . . 38

5.2 DUST CONTROL . . . . . . . . . . . . . . . . . . 39

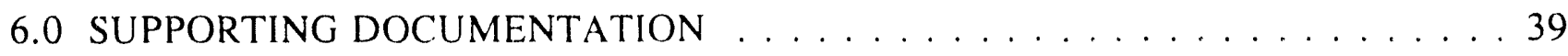

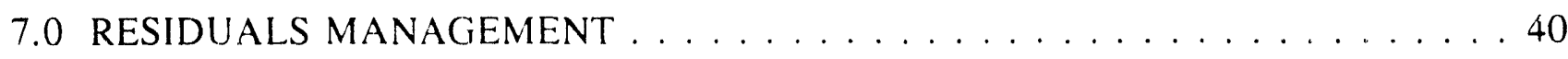

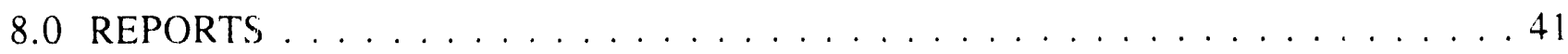

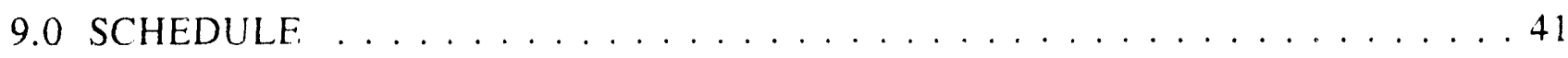

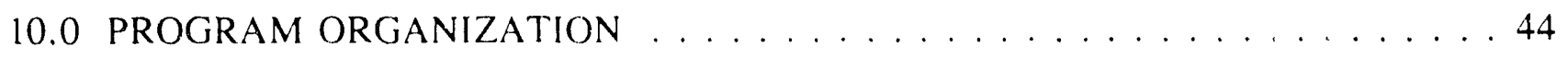

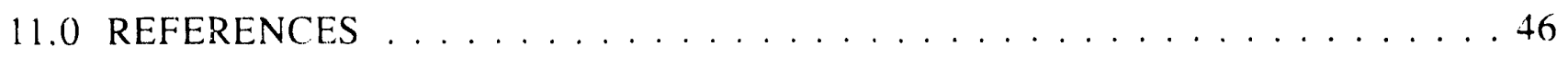

\section{APPENDIX:}

A - SAMPLING AND ANALYSIS REQUIREMENTS ................ A

\section{FIGURES:}

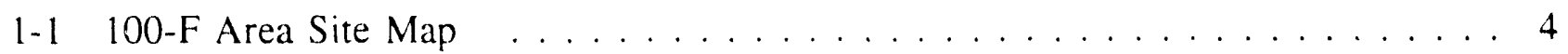

9-1 100 Area Excavation Treatability Test Schedule . . . . . . . . . . . . . 42

9-2 Integrated Treatability Schedule . . . . . . . . . . . . . . . . 43

10-1 100 Area Excavation Treatability Test Program Organization . . . . . . . . . . 45

\section{TABLES:}

1-1 Potential Contaminants in the $116-\mathrm{F}-4$ Pluto Crib $\ldots \ldots \ldots \ldots$

2-1 Fraction of Allowable Exposure from Excavation of 100-B/C Waste Sites Without Any Dust Control . . . . . . . . . . . . 10 


\section{CONTENTS (cont)}

\section{TABLES (cont)}

2-2 Recommended Instrumentation for Analyzing Radionuclides in the Field . . . . . . . . . . . . . . . . . . . 14

3-1 Potential ARAR and Cleanup Standards for Comparison of the Excavation Treatability Test Results . . . . . . . . . . . . . . . . . 23

3-2 Data Quality Objectives for the Excavation Treatability Test Plan, Dust Control, Baseline ................... 25

3-3 Data Quality Objectives for the Excavation Treatability Test Plan, Dust Control. Water Sprays . . . . . . . . . . . . . . 26

3-4 Data Q!lality Objectives for the Excavation Treatability Test Plan, Dust Control, Water with Additives . . . . . . . . . . . . . 27

3-5 Data Quality Objectives for the Excavation Treatability

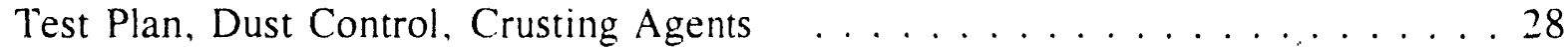

3-6 Data Quality Objectives for the Excavation Treatability Test Plan, Field/laboratory Radionuclide Analysis Correlation, Gamma Pulse Height Analysis 29

3-7 Data Quality Objectives for the Excavation Treatability Test Plan, Field/Laboratory Radionuclicie Analysis Correlation, Gross Beta Test _. . . . . . . . . . . . . . . . . 30

3-8 Data Quality Objectives for the Excavation Treatability Test Plan. Field/Laboratory Radionuclide Analysis Correlation, Gamma Detection from Transuranics 
DOE/RL-93-04, Rev. 1 
DOE/RL-93-04. Rev. 1

\subsection{PROJECT DESCRIPTION}

\subsection{INTRODUCTION}

This test plan documents the requirements for a treatability study on field radioncalide analysis and dust control techniques. These systems will be used during remedial actions involving excavation. The data from this treatability study will be used to support the feasibility study (FS) process. Development and screening of remedial alternatives for the 100 Area, using existing data, have been completed and are documented in the 100 Area Feasibility Study, Phases 1 and 2 (DOE-RL. 1992c). Based on the results of the FS, the Treatability Study Program Plan (DOE-RL 1992f) identifies and prioritizes treatability studies for the 100 Area. The data from the treatability study program support future focused FS, interim remedial measures (IRM) selection, operable unit final remedy selection, remedial design, and remedial actions.

Excavation is one of the high-priority, near-term, treatability study needs identified in the program plan (DOE-RL 1992f). Excavation of contaminated soils and buried solid wastes is included in several of the alternatives identified in the 100 Area FS. Although a common activity, excavation has only been used occasionally at the Hanford Site for waste removal applications. The most recent applications are excavation of the 618-9 burial ground and partial remediation of the $316-5$ process trenches (DOE-RL 1992a, 1992b). Both projects included excavation of soil and dust control (using water sprays).

Excavation is a well-developed technology and equipment is readily available; however, certain aspects of the excavation process require testing before use in full-scale operations. These include the following:

- measurement and control of excavation-generated dust and airborne contamination

- verification of field analytical system capabilities

- demonstration of soil removal techniques specific to the 100 Area waste site types and configurations.

The execution of this treatability test may produce up to $500 \mathrm{yd}^{\mathrm{j}}$ of contaminated soil, which will be used for future treatability tests. These tests may include soil washing with vitrification of the soil washing residuals. Other tests will be conducted if soil washing is not a viable alternative.

\subsection{PURPOSE AND SCOPE}

The purpose of this treatability test is to generate data supporting the detailed analysis and design of excavation operations. Data are obtained by correlating field and laboratory analysis for radionuclides and by demonstrating the effectiveness of dust control measures. 
The correlation between field instrument results and standard laboratory analytical results is used during full-scale excavations to identify the contaminated regions of a site without the need for long turnaround samp!e analysis in a fixed laboratory. The dust control measures are important at a waste site if the excavation operation generates significant levels of dust and/or the dust contains regulated amounts of contaminants.

This treatability test plan outlines the objectives, techniques, and procedures for conducting remedy selection and remedy design of field analysis and dust control systems. The data from these tests will be used to support future treatability studies, focused FS, and IRM by establishing or identifying the following:

- effectiveness and applicability of dust control and field analytical techniques to the 100 Area soils

- demonstration of each technique's ability to meet applicable or relevant and appropriate requirements (ARAR) and cleanup standards

- refinement of process and equipment requirements for cost estimation purposes.

The scope of this test plan includes definition of the following:

- test goals

- performance goals

- sampling and analysis requirements

- data handling

- residuals management

- community relations

- reports

- equipment and materials

- potential ARAR

- schedules.

\subsection{SITE DESCRIPTION}

\subsubsection{Site Selection}

The program plan (DOE-RL 1992f) documents the methodology used to identify and select the sites for treatability studies. This excavation study is designed to demonstrate the following:

- a correlation exists between field screening measurements and laboratory results

- dust generated during excavation operations can be effectively suppressed

- excavation operations will not spread contamination to uncontaminated areas. 
Therefore, the parameters for selection of an excavation treatability study site are

- a site where excavation will be used as part of the remedial action (i.e., soil sites)

- a site containing sufficient levels of radioactivity so that field instruments can be effectively used to measure contamination levels, i.e., contaminants are above background

- a site with a relatively small volume of contamination to minimize the volume requiring storage or disposal after the test

- a site where remediation will produce minimal impacts to any nearby waste sites.

The site chosen for this study is the 116-F-4 pluto crib. This crib lies in the 100-FR-1 Operable Unit, approximately $120 \mathrm{ft}$ southwest of the $105-\mathrm{F}$ reacin building (see Figure $1-1)$. This crib is a soil site, has radiological contamination levels sufficient for field measurements, and is one of the smallest sites in the 100 Area.

\subsubsection{Site History}

The 116-F-4 pluto crib is a 10- by 10-ft timber structure filled with sand or gravel and located approximately $8 \mathrm{ft}$ below grade. It received approximately 1,057 gal of cooling water from individual process tubes contaminated as a result of fuel cladding failures. Water contaminated with an estimated $280 \mathrm{C}$ i of fission products was discharged to this crib during its operating period from 1950 to 1952 (Dorian and Richards 1978). After use, the crib was covered with a layer of soil.

\subsubsection{Nature and Extent of Contamination}

The nature and extent of contamination are based on samples collected by Dorian and Richards (1978). These samples were taken in 1976 and analyzed solely for radionuclides. Results from the samples indicate elevated concentrations of plutonium-239/240, strontium-90, and cesium- 137 with maximum concentrations as high as $5.400 \mathrm{pCi} / \mathrm{g}$ for cesium-137. The concentrations decrease up to three orders of magnitude with depth (to 20 $\mathrm{ft})$. In addition to this quantitative data. other important information sources include intrusive investigations into analogous sites and interviews with personnel familiar with the waste site.

The only potential chemical contaminant is chromium, originating as an algicide in the cooling water. Preliminary results from current limited field investigation (LFI) activities in the 100-F Area indicate that chromium is not above background levels. As additional validated data from the LFI activities become available, they will be reviewed for potential effects on this treatability study. 
DOE/RL-93-04, Rev. 1

Figure 1-1. 100-F Area Site Map.

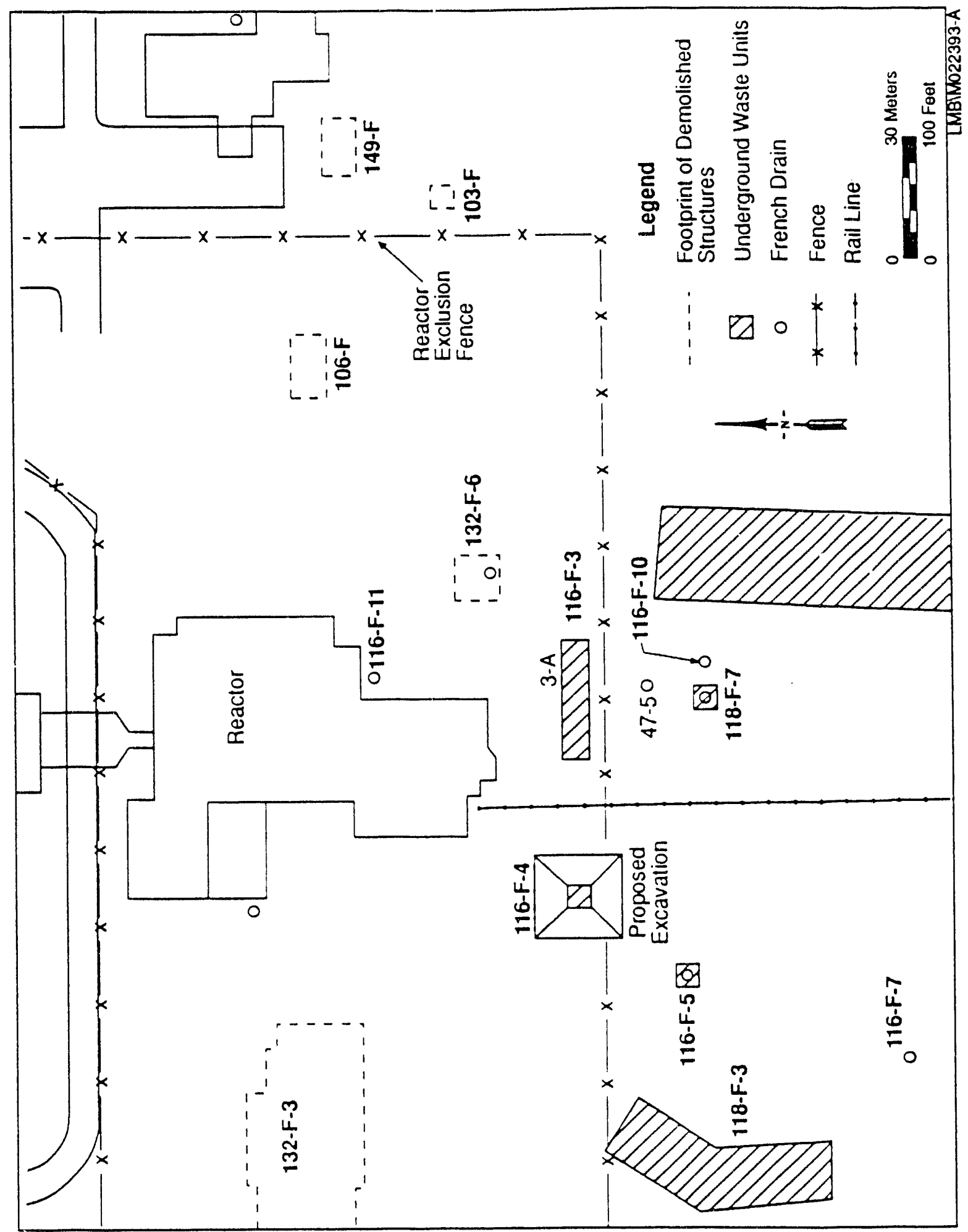


In the Dorian and Richards (1978) study. the contamination from the 116-F-4 pluto crib was estimated to extend over a $30-\mathrm{ft}^{2}$ area to a depth of $25 \mathrm{ft}$. Recent estimates, taking the high vertical conductivity of the Hanford formation into consideration, place the contaminated area no larger than $20 \mathrm{ft}^{2}$. The actual area of contamination will not be known until excavation; however the $20 \mathrm{ft}^{2}$ estimate is a reasonable upper bound. The lower bound is an area equal to the crib dimensions $\left(10 \mathrm{ft}^{2}\right)$. Table $1-1$ lists the average and maximum contaminant concentrations, throughout the volume defined by Dorian and Richards, as well as the soil performance level. Performance levels are the levels that the treatability test should meet to be successful. The performance levels represent the presumed cleanup levels without the benefit of a signed record of decision.

Table 1-1. Potential Contaminants in the 116-F-4 Pluto Crib.

\begin{tabular}{|c|c|c|c|c|}
\hline Radionuclide & $\begin{array}{l}\text { Type of } \\
\text { Radiation }\end{array}$ & $\begin{array}{l}\text { Maximum } \\
\text { Concentration } \\
(\mathrm{pCi} / \mathrm{g})\end{array}$ & $\begin{array}{c}\text { Average } \\
\text { Concentration } \\
(p \mathrm{Ci} / \mathrm{g})\end{array}$ & $\begin{array}{c}\text { Performance } \\
\text { Level }^{\mathrm{b}} \\
(\mathrm{pCi} / \mathrm{g})\end{array}$ \\
\hline $2.392+11 \mathrm{Pu}$ & Alpha, Gamma & 110 & 35 & 75 \\
\hline "Sr & Beta & 1.973 & 723 & 13 \\
\hline${ }^{15} \mathrm{Eu}$ & Beta, Gamma & 8.48 & 3.60 & 3 \\
\hline${ }^{14} \mathrm{Eu}$ & Beta, Gamma & 62.2 & 19.9 & 3 \\
\hline${ }^{1.37} \mathrm{Cs}$ & Beta, Ganma & 3.657 & 1.084 & 3 \\
\hline
\end{tabular}

"Concentrations decayed to 1993.

"Accepted upper limit of radioative material concentrations for soils (WHC 1988. Table K-1).

Source: Dorian and Richards 1978.

Site volume is $23.000 \mathrm{ft}$.

Site mass is $1.6 \times 10^{\circ} \mathrm{g}$.

\subsection{TREATABILITY STLDY DESCRIPTION}

Treatability studies are primary components of the remedial investigation/ feasibility study (RI/FS) process, providing critical performance and cost information to evaluate and select remedial alternatives. Treatability studies also provide design information necessary to implement the selected remedy.

Treatability studies are performed in three progressive phases - remedy screening, remedy selection, and iemedy design. The scope of this test plan includes the remedy selection and design phases for the field laboratory radionuclide analysis correlation and dust control test. The remedy selection phase will provide data to support evaluation of the excavation option in future FS for IRM or final operable unit remedies. Performance data from these tests will indicate whether ARAR or cleanup goals can be met at the site by using 
field analysis and dust control techniques. The remedy selection tests will also allow estimation of costs associated with implementation to the accuracy required for the FS $(+50 \%$ to $-30 \%)$. The remedy design phase is performed to optimize the process and to obtain detailed cost and performance data for full-scale excavation field monitoring and dust control systems design.

\subsection{FULFILLMENT OF MILESTONES}

Completion of this treatability test satisfies the 100-HR-1 Operable Unit work plan (DOE-RL 1992e) interim milestone M-15-05B, established in the Hanford Federal Facility. Agreement and Consent Order (Tri-Party Agreement) (Ecology et al. 1989) change control form number M-15-92-11, dated December 3, 1992. The excavation treatability study counts for the 100-HR-1 work plan treatability milestone. The interim milestone completion date is November 30, 1993. The milestone is considered completed at completion of the field activity. In addition to M-15-05B, a milestone (or milestones) will be established which will include treatment of the excavated soil.

\subsection{TECHNOLOGY DESCRIPTIONS}

\subsection{DUST CONTROL}

Dust control is the practice of controlling the amount of particulate matter suspended in air. Dust control is important during remediation because inhalation of dust particles $(\leq 10$ $\mu \mathrm{m}$ diameter) is considered a human health risk, and dust particles may contain contaminants that present an environmental and health threat.

The generation of dusts generally depends on the soil moisture content, the amount of energy delivered to the soil (such as wind speed or drop height), and the fraction of the soil that is easily entrained into the air (material silt content). Therefore, control of dust generation requires controlling one or more of these factors.

A convenient method of measuring the amount of dust control obtained in an operation is to compare the dust generation rates before and after control measures are used. The factor used is the dust control efficiency. and is defined in the following equation (Cowherd et al. 1990):

$$
R=A e(1-C)
$$

where:

$\mathrm{R}=$ estimated mass emission rate. $\mathrm{lb} / \mathrm{yr}$.

$\mathrm{A}=$ source extent. $\mathrm{ft}^{2}$. 


$$
\begin{aligned}
& \mathrm{e}=\text { uncontrolled emission factor, } \mathrm{lb} /\left(\mathrm{ft}^{2} \mathrm{yr}\right) \\
& \mathrm{C}=\text { fractional control efficiency. }
\end{aligned}
$$

Empirical formulas for generation of dust during different activities have been documented in the Compilation of Air Pollution Emission Factors (EPA 1988). These formulas present the relation between emission factors and the moisture content, energy delivered to the soil, and particle size variables. By reviewing the formulas, it is possible to determine which factor should be controlled in a specific dust generating situation. The two situations of concern for this study are equipment generated and wind generated dust emissions.

For the equipment-generated dust emissions test, the excavation is performed using a backhoe and potentially a front-end loader. Because the dust-generation rate from a frontend loader is considered greater than a backhoe, the formula for front-end loader emissions is used. The emission factor for front-end loader operations is given in Compilation of Air Pollutant Emission Factors (EPA 1988) and is based on material-handling operations at a steel mill. All sources (track. tires, bucket, dump) are represented by this factor, which is given as:

$$
E=X(0.0018) \frac{\left(\frac{s}{5}\right)\left(\frac{U}{5}\right)\left(\frac{H}{5}\right)}{\left(\frac{M}{2}\right)^{2}\left(\frac{Y}{6}\right)^{0.33}}
$$

where:

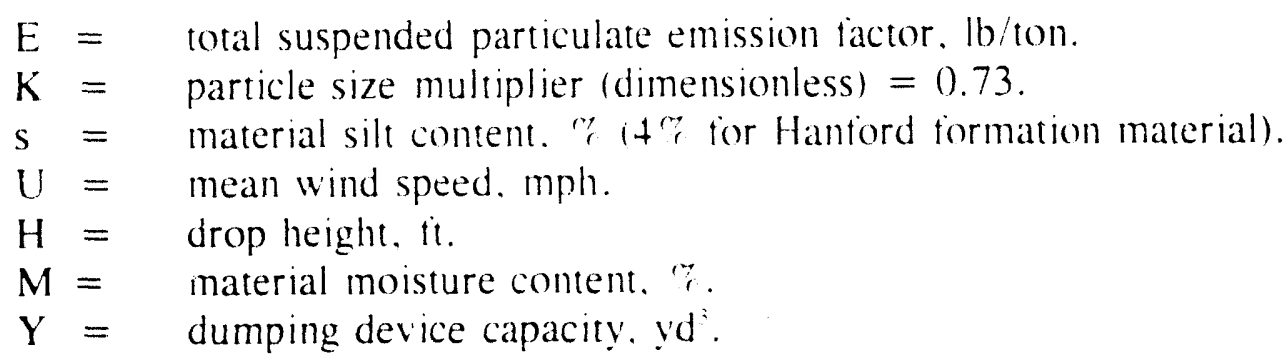

The main parameters open to control during excavation are the drop height and material moisture content. Of all the parameters, the soil moisture content has the largest impact on the emission factor. Therefore. controlling moisture content provides the greatest level of control on the dust emissions. The moisture content is usually controlled by adding water or modifying the surface of moist soils to reduce water transport to the atmosphere. Because new soil surfaces are continuously being exposed in an excavation. the only practical way to control dust is to increase the moisture content by adding water. This can be accomplished with water sprays. mists, or fogs. Foams may add moisture to the soil but significantly less than water sprays. 
Typically water is added to soil by an rea spray or spray curtain, and foams can be applied as a spray curtain or laid down on the soil surface. The U.S. Environmental Protection Agency (EPA) Dust Control at Hazardous Waste Sites (1985) details a series of tests performed on dust control effectiveness during movement of soils. From these tests, EPA found that water sprays were effective at reducing dust emissions during the dump cycle and that addition of surfactant (at 1:1000 dilution) increased control efficiencies slightly while allowing reduced water use. The spray curtains and foam applications showed smaller increases in the control efficiencies.

Wind erosion of exposed areas or piles occurs in the following ways:

- soil transport by surface creep

- saltation

- suspension.

Surface creep is the rolling and sliding movement of particles across a surface. These particles generally have a diameter in excess of $1,000 \mu \mathrm{m}$; they can be lifted by the wind but are too heavy to remain airborne. Saltation is the hopping and bouncing movement of a particle across a surface. These particles. with diameters from 80 to $1,000 \mu \mathrm{m}$, are lifted by the wind but are also too heavy to remain airborne. Particles smaller than $80 \mu \mathrm{m}$ are generally moved by suspension. EPA (1985) reports that from 3 to $40 \%$ by weight of the total soil loss from exposed areas is attributable to suspension. Between 50 and $75 \%$ of the total soil loss is from particles moved by saltation. and from 5 to $25 \%$ from surface creep.

Wind erosion is usually an intermittent activity that occurs above a threshold wind velocity. Estimates of this threshold velocity vary from about 10 to $20 \mathrm{mph}$ across different soil types, aggregates, and meteorological conditions (Cowherd et al. 1990).

The following wind erosion emission factor equation is the most commonly used to estimate erosion from storage piles (EPA 1979):

$$
E=1.7\left(\frac{s}{1.5}\right)\left(\frac{365-p}{235}\right)\left(\frac{f}{15}\right)
$$

where:

$\mathrm{E}=$ total suspended particulate emission factor. $\mathrm{lb} /$ day/ac.

$\mathrm{s}=$ silt content of aggregate. $\%(4 \%$ for Hanford formation material $)$.

$\mathrm{p}=$ number of days per year with $\geq 0.0 \mathrm{l}$ in of precipitation.

$f=$ percentage of time that the unobstructed wind speed exceeds $12 \mathrm{mph}$ at the mean pile height.

Equation (3) is based on the assumption that wind erosion emissions vary with soil particle size, moisture, and wind speed. In general. wind erosion control systems work in one of iwo ways: (1) by reducing wind speed on the soil surface. or (2) by forming a new. 
less-erodible surface. The following methods can be used to reduce wind speed on the soil surface:

- covering the pile with a wind-impervious fabric or vinyl

- erecting a windscreen

- reorienting soil pile.

The soil piles for this test are being actively worked; therefore, covering them to reduce wind speed is not an option. For reduction of wind speed, the only applicable methods are windscreens and pile orientation. While neither method is very effective, windscreens provide slightly more control of the wind effects.

Methods for forming a new, less-erodible, surface include:

- spraying water to compact and weigh soli particles

- applying chemical dust suppressants to form a crust over the existing soil or to bind the top soil particles together

- establishing vegetation.

The products that form new, less-erodible, surfaces are only applicable to areas that will not be actively worked by equipment, such as storage piles. Establishing vegetation is not considered an option because the soil piles are transient and are removed after the test.

From the discussion above, three general methods are applicable for this test to reduce fugitive dust emissions from soils: (1) reducing the wind speed at the soil surface, (2) increasing the soil moisture content, and (3) changing the soil surface to be less erodible.

\subsubsection{Windbreaks}

To assess the need for weather shelters as dust control during waste site remediation, a value engineering study was conducted by Los Alamos Technical Associates. Inc.

(WHC 1992). Assumptions included the following:

- excavation by conventional equipment, such as rubber-tired front end loaders and tracked backhoes

- no dust control measures

- dust generated from overburden removal, overburden replacement, backfill, and recontouring was not considered in the study

- soil particles $50 \mu$ and smaller (approximately $10.5 \%$ of the total soil weight) can be aerosolized. 
Allowable exposure rates (in millirem per year) to onsite and offsite personnel were generated by computer program. Exposure rates based on the project assumptions were determined. The results of the study are presented in Table 2-1 as ratios between the anticipated exposures from operations and the allowable exposures. The conclusion of the study was that "...excavation and material handling can be conducted in an open-air environment without exceeding onsite or offsite regulatory limits" (WHC 1992). The authors of the study also pointed out that, while the analysis did not assume any dust control measures or any refinement of transfer methods for waste materials, dust control measures should be provided, and the number of open-air transfers should be minimized to reduce the onsite and offsite individual dosages consistent with the as low as reasonably achievable (ALARA) principle. This treatability study is aimed at identifying the dust control measures necessary to protect workers, to meet ALARA, and to comply with ARAR. Dust control measures will be studied to determine the need for dust control and to determine the most effective method of dust control.

Table 2-1. Percent of Allowable Exposure fro $A$ Excavation Operations at 100-B/C Waste Sites Without Weather Shelters.

\begin{tabular}{|l|l|l|}
\hline \multirow{2}{*}{ Site Type } & \multicolumn{2}{|c|}{ Exposure to } \\
\cline { 2 - 3 } & \multicolumn{1}{|c|}{ Noninvolved Onsite Personnel } & \multicolumn{1}{c|}{ Offsite Personnel } \\
\hline Solid Waste & $0.5 \%$ & $0.2 \%$ \\
\hline Liquid Waste & $9.5 \%$ & $4.6 \%$ \\
\hline
\end{tabular}

The allowable daily exposure limits for each radionuclide are listed in Appendix D of the LATA study (WHC 1992).

Studies have been conducted on the effectiveness of windscreens versus chemical dust suppressants. In one study (Rosbury 1985), chemical dust suppressants were found to be superior to windscreens for controlling dust in terms of effectiveness, cost, and mobility around the pile. The analysis also indicated that the windscreen did not produce significant reductions in concentrations in the $<10 \mu \mathrm{m}$ respirable size range. In the referenced study, the screen did reduce wind speeds by the amount anticipated, but this did not result in proportionate reductions in particulate concentrations coming from the pile.

\subsubsection{Water Sprays}

Water sprays reduce airborne dust by producing small water droplets that impact and encapsulate dust particles. Dust is suppressed because the particle bulk density increases and wetted particles agglomerate (Termine and Favilla 1987). Water sprays are applied by nozzles with course openings (water spray), medium openings (mists), or fine openings (fogs). To improve the effectiveness of water sprays, surface-active wetting agents are added to the spray water, typically at concentrations of 0.05 to $2 \%$. The wetting agents increase the water's ability to wet material and may result in improved dust control/reduced water consumption. Generally. water sprays effectively knock down airborne dust and are 
positioned to treat the location rather than the material. For excavation, it is recommended to water spray the soil prior to excavation, fog spray selected areas during excavation, and fog spray the placement of the soil into bins, trucks, or stockpiles.

\subsubsection{Charged Water Sprays}

Because dust and industrial pollutants carry a natural electrical charge as they move through the air, collision of airborne dust and similarly sized water droplets produces particle agglomeration and knockdown. The magnitude of the water droplet charge produced by a fogger is $10^{6}$ greater than the natural charge on the particles. The charged fog is created by passing the atomized droplets of the fog through an induction ring to induce an electrical charge, either positive or negative, depending on the polarity of the dust.

Bigu and Grenier (1989) tested the effectiveness of a charged water spray in an underground uranium mine for controlling long-lived radioactive dust and short-lived aerosol concentrations during rock breaking and ore transportation. McCoy et al. (1985) developed an innovative method for measuring dust reduction in the laboratory and presented data for dust reduction effectiveness of hydraulic and charged water sprays and a water-powered scrubber system.

While the initial results of the literature survey suggest that charged water sprays should be considered for testing in the 100 Area, further analysis indicates that outdoor applications had not been successful. Because the charged fog requires some residence time to interact with the dust, even a slight breeze disperses the dust and prevents effective dust knockdown. Based on this information, the charged water spray system is eliminated from consideration in this treatability study.

\subsubsection{Crusting Agents}

Liquid crusting agents are sprayed onto the soil surface. The crusting agents penetrate the surface and, when dry, form a cohesive, durable crust that prevents erosion, nuisance dust, and material losses on excavation surfaces and stockpiles. Termine and Favilla (1987) stated that polymer-based products such as latex were superior to lignins and waste oils for coal applications. For the 100 Area excavation, the use of crusting agents will only be effective during periods when the excavation is not active because the excavation operations will break the surface crust and allow dust generation.

Bench-scale tests conducted at the Idaho National Engineering Laboratory showed that chemical dust suppressants are effective for controlling dust spread (Winberg and Wixom 1992. Duce et al. 1989. and Duce et al. 1988). Chemical dust suppressants, or crusting agents, may produce a tough surface without the need for repeated application; therefore, they will be tested for applicability in the 100 Area for inactive areas. 


\subsubsection{Foams}

Dust control foam has a low surface tension and consists of thousands of small interconnected bubbles that contact and encapsulate fine dust particles (Termine and Favilla 1987). While not useful for knocking down airborne dust, foams are effective in preventing the creation of airborne dust. Foam systems generally require $90 \%$ less moisture than water spray systems. Foams are mostly air with a higher surface area per unit volume of moisture than water droplets. A foam is produced by adding a foaming agent to water and metering the solution, along with air, into a foaming chamber. The resulting foam is then sprayed through nozzles onto the dust-forming material.

Page and Volkwein (1986) indicate that foams have been used for dust control since shortly after the enactment of the Coal Mine and Safety Act of 1969. Dust reduction was found to be up to $48 \%$ greater with low-expansion foam than with water sprays alone. Testing by Monsanto Research Corporation, under contract to the U.S. Bureau of Mines, indicated that high-expansion foam was $15 \%$ to $20 \%$ more effective than water sprays in suppressing respirable coal dust (Page and Volkwein 1986). This test also generated statistical data indicating that foam was $50 \%$ more effective than water sprays in suppressing total coal dust.

Foams for dust suppression are not proposed for testing in this program because of concerns with future treatment of the soil and the uncertainty of its effectiveness. Foams are typically used to treat discreet areas where dusts are generated, such as conveyor drop points or a mining equipment cutter. Controlling dust with foam over an entire excavation face is not practical. Also, the contaminated soil from this test may be used in the soil washing treatability test. The soil washing treatment relies on the separation of the fine fraction from the soil matrix, and because the foaming agents work by agglomerating particles, they may interfere with that separation. However, foams may be tested in future treatability studies if effective methods are identified for application to large-scale excavations.

Of these technologies, water sprays, water sprays with surfactants, and crusting agents are chosen for testing in this program.

\subsection{FIELD/LABORATORY RADIONUCLIDE ANALYSIS CORRELATION}

Radionuclides can be measured by a variety of methods ranging from simple detection of gross activity (such as gross alpha, beta, and gamma) to the complex radionuclide-specific measurements based on radiation energy profiles (such as gamma spectral logging). The excavation operations identified for remediation of the Hanford Site require near-real-time measurement of radionuclides (identifying specific radionuclides and concentrations) for waste designation and excavation control. The simple methods can be used in the field; however, these do not identify specific contaminants or concentrations. The radionuclidespecific measurement techniques are typically performed in fixed laboratories. Therefore, this test will be performed to determine if field radiation measurements can be correlated to 
laboratory analyses to allow field measurements to identify radionuclide species and concentrations.

The objective of a field/laboratory radionuclide analysis correlation is to compare and establish a correlation between in situ field measurements and laboratory analyses. The correlation is derived from the data range extending from 1/3 the performance limit to 3 times the performance limit for each radionuclide. An index of error, such as the Pearson correlation ( $r$ ) or $r^{2}$ is used to quantify the fit of the correlation to the data. The most critical part of this test is selection of instrumentation. The many types of instruments and methods for detecting radiation may or may not be effective at discriminating between individual radionuclide contaminants in the soil matrix. The effectiveness of a particular field screening device may be related to the specific radionuclide and potential effects from the soil matrix being screened. The field/laboratory radionuclide analysis correlation results in selection of one or more devices that can guide excavation during actual remediation.

In situ radiation measuring devices are assessed to determine if sufficient sensitivity could be obtained to discriminate radionuclide concentrations at or below performance levels. This involves comparing instrument sensitivities and response characteristics to background radiation levels and interferences from other radionuclides. Background and cosmic radiation have been considered and will not affect the results of field screening for radionuclides. The contaminant radionuclides are, in general, aged mixed fission products and include alpha, beta, and gamma emissions. The level of background radiation is the first consideration in detecting any of these radionuclides. Other important considerations include the sample matrix and interfering radionuclides. Table 2-2 presents the instruments recommended for each type of radiation.

\subsubsection{Gamma Radiation}

Gamma radiation can be detected by a variety of techniques and discriminated by energy to identify specific radionuclides. thus leading to improved identification and lower background (the background level at any specific energy level is less than the total).

Background gamma radiation comes principally from the natural uranium series, natural thorium series, and potassium-40. The gamma radiation from uranium and thorium can be attributed primarily to decay progeny, which are usually found in equilibrium with the parent radionuclide.

The major background gamma contribution from soil occurs within approximately the first $25 \mathrm{~cm}$ below the surface. Higher energy gammas from a depth of $25 \mathrm{~cm}$ are attenuated by about $90 \%$. The attenuation process produces scattered photons of lower energy than the original gammas. This results in a continuum of photon energies lower than the original gamma. The energy spectrum available for detection, therefore, is a continuum of scattered photons with unscattered photons superimposed. The detected spectrum will depend on the characteristics of the detecting device. 
DOE/RL-93-04, Rev. 1

Table 2-2. Recommended Instrumentation for Analyzing Radionuclides in the Field.

\begin{tabular}{|c|c|c|c|c|}
\hline $\begin{array}{l}\text { Type of } \\
\text { Radiation }\end{array}$ & Method & Instrument & $\begin{array}{l}\text { Type of } \\
\text { Analysis }\end{array}$ & Technique \\
\hline Gamma & Gross ganma & Sodium iodide & Single channel & \\
\hline Gamma & Gamma pulse height analysis & $\begin{array}{l}\text { Germanium or } \\
\text { sodium iodide }\end{array}$ & Multichannel & \multirow{3}{*}{$\begin{array}{l}\text { Region of } \\
\text { interest } \\
\text { or } \\
\text { ratio }\end{array}$} \\
\hline Gamma & Gamma from transuranics & $\begin{array}{l}\text { Germanium } \\
\text { (extended range) }\end{array}$ & Multichannel & \\
\hline Beta & Bremsstrahlung detection & Germanium & Multichannel & \\
\hline Beta & Gross beta & Large area heta & & \\
\hline Alpha & Concentration from correlation ${ }^{*}$ & & & Paper Study \\
\hline
\end{tabular}

"This is a comparison of transuranic materials to detectable gamma emitters. Once proven, the ratio derived from this study could be used to inter concentrations on transuranics from detectable radionuclide concentrations.

Calculation of a concentration of contaminant radionuclides will require an assumption that the radionuclides are approximately uniformly distributed. Using this assumption, two bounding errors are possible. When all radionuclides are concentrated near the surface, little attenuation occurs, and the concentration derived over the $25-\mathrm{cm}$ depth is higher than the actual average concentration. When the radionuclides are concentrated near the bottom of the $25-\mathrm{cm}$ depth, large attenuation occurs, and the concentration derived over the depth is lower than the actual average concentration. Two methods for detecting gamma radiation are gross gamma and gamma pulse herght analysis.

2.1.2.1 Gross Gamma. Gross gamma count rate is used to detect an increase above the background gamma count rate, not to identify specific radionuclides. Gross gamma is usually only effective as a screening technique. The background count rate depends on the efficiency, the volume, the surface area, and the field of view of the device. A sodium iodide detector yields the highest sensitivity for common detectors. The recommended detector is a 3-by 3-in. cylindrical detector with 2-in.-thick annular lead shield to reduce background from the sides and restrict the field of view.

When used for screening, a gross gamma detection limit that equals the performance limit of the most restrictive gamma-emitting radionuclide ensures that all gamma-emitting radionuclides are below their performance level. Moisture content and type of soil affects the calibration of the devices for determining concentrations of radionuclides. Moist soils 
give an apparent lower concentration than dry soils. Because coarse soils with few fines are less dense than soils composed only of fines. they give a higher apparent concentration than fine soils.

2.2.1.2 Gamma Pulse Height Analysis. Gamma pulse height analysis generates information on individual radionuclides because it is restricted to the characteristic energy of the radionuclide gamma emission or a band centered around that energy. A lower detection limit is achieved because only the background radiation near the characteristic energy is detected. Shielding is recommended as in gross gamma analysis to limit the background and contaminant signals to the sample area.

Pulse height analysis can be performed in two ways: (1) obtain the gross counts in an energy band or window that may be characteristic of a single radionuclide (single-channel analysis); or (2) obtain information from a broad energy region to analyze a spectrum of energies for multiple radionuclide identification and analysis (multichannel analysis). Singlechannel analysis usually employs robust and inexpensive equipment (such as sodium iodide detectors). Multichannel analysis equipment can be constructed with equal robustness, but the added sophistication invites more opportunity for failure.

Should single-channel analysis be adequate, multiple measurements can be made using several devices in parallel. The total equipment cost for these units may be less than a multichannel device. These simpler devices are also available at a small additional cost with up to four windows. One or more extra windows allow a simultaneous determination of background. This reduces the sample collection time, allows a better determination of natural background, and decreases the detection limit. The natural radionuclide spectrum is generally unchanging in a small area, although soil horizons may exhibit large changes. The largest natural changes tend to be in the concentration of potassium-40. A technique to minimize the effect of a changing background spectrum is to ratio regions of the natural spectrum to detect such changes and to ratio the contaminant window to natural windows. Dividing the energy spectrum at the potassium-40 energy and determining the ratio of the counts above and below this energy region minimizes the effect of changing potassium- 40 concentration. All contaminant radionuclides of interest in the test site have energies less than that of potassium-40.

The gamma pulse height analysis can also be used to detect the low energy photons from bremsstrahlung radiation (the energy emitted by an electron accelerated in its collision with the nucleus of an atom) and transuranic radionuclides (via association with americium-241), although detection may be difficult.

2.2.1.3 Gamma Detection from Transuranics. Gammas from plutonium-239 are too infrequent to consider. However, americium-241 is usually associated with plutonium-239 and has a $60 \mathrm{keV}$ gamma at a frequency of $36 \%$ of decays. This may be used to estimate the concentration of plutonium-239 if the ratios are known, background interference is low. and an extended range germanium detector is used (greater efficiency for low energy photons). Soil moisture will be critical to such a measurement. As an example: 
An unshielded, high-efficiency germanium detector will collect on the order of 200 counts per minute per channel, at a gain of $0.5 \mathrm{keV}$ per channel, in the $60-\mathrm{keV}$ region. If a region 10-channels wide is used to deteci the americium-241 gamma, 2,000 counts per minute will be collected. A 15minute count will result in 30,000 counts with a detection limit of 800 counts. If this is assumed to come primarily from the first $2 \mathrm{~cm}$ of an area of $1 \mathrm{~m}^{2}$ and to be collected at an efficiency of $1 \%$, the americium-241 is present at about 7 $\mathrm{pCi} / \mathrm{g}$. If plutonium-239 to americium-241 ratio is 5 , the plutonium has a concentration of $35 \mathrm{pCi} / \mathrm{g}$. This value is less than the performance limit ( $75 \mathrm{pCi} / \mathrm{g}$ ), thus this technique may be applicable. However, the soil contains, in addition to natural radionuclides, contaminant radionuclides. The cesium-137 average concentration is about $40 \mathrm{pCi} / \mathrm{g}$. This and other radionuclides may raise the background in the $60 \mathrm{keV}$ region by more than a factor of 10. A factor-of-10 increase raises the detection limit a factor of 3 . Therefore, the best detection limit for plutonium-239 may be higher than $105 \mathrm{pCi} / \mathrm{g}$.

The more sophisticated technique of obtaining a full energy spectrum by multi-channel analysis may be necessary to obtain the required detection limits, particularly for the low energy gammas for transuranic detection. Multichannel analyzers can also be used for windows, called regions of interest. Region-of-interest tests limit the energy range to the gamma energy of interest and can allow multiple regions of interest to be analyzed simultaneously. These regions can be used to identify and quantify specific radionuclides or, for background regions, for better detinition of background levels. Programs are also available for spectral stripping and deconvolution of overlapping energy peaks for improved identification and quantification. This technique is also necessary for detection of the low energy bremsstrahlung radiation.

Detectors for either type of test should be sodium iodide detectors at least 3 by 3 in. or high purity germanium detectors (also known as intrinsic germanium detectors). The germanium detectors should be as large as possible. while maintaining high efficiency. The sodium iodide detectors are more robust, have a higher efficiency, and require less care. The germanium detectors are less robust and require cooling. The sodium iodide detectors are less precise, exhibiting a lower resolution for the gamma energy spectrum. Therefore, a broad energy span is required for the region of interest and a higher region of interest background is detected. The lower resolving power of the sodium iodide detector restricts the ability to discriminate between background and contaminant energies. The sodium iodide detector may be completely adequate for most cases and may be the only choice if robustness and the ability to physically conform to a measurement situation is required. The germanium detector is physically restricted to low vibration conditions and situations that can accommodate the cooling system (Note: this cooling system may be liquid nitrogen or thermoelectric based.)

Another type of field measurement can be made, once soil is removed, that will give a higher sensitivity by maximizing detector field of view (called enhanced geometry gamma detection). To provide enhanced geometry gamma detection. a straight-sided 5-gal container 
is fitted with a concentric tube of a diameter that will allow an unshielded sodium iodide detector to fit inside. The annular volume is filled with soil and the gamma radiation is measured. The enhanced geometry measurement should attain a higher sensitivity and a lower detection limit with a similar count time.

\subsubsection{Beta Radiation}

Beta radiation can be detected by a variety of techniques and can be discriminated by energy for improved identification and lower background. Energy discrimination is generally not practical for field work and is not recommended for this application. Strontium-90 is the only radionuclide at the test site that emits solely beta radiation.

The background beta radiation can be attributed principally to the natural uranium series, natural thorium series, and potassium-40. The beta radiation from uranium and thorium comes from decay progeny, which are usually found in equilibrium with the parent radionuclide.

The background beta contribution from soil comes from about the first $0.5 \mathrm{~cm}$ below the surface. All beta spectra are a continuum of energies. A specific radionuclide can be identified by the shape of the spectrum and the end-point energy. The attenuation process produces scattered electrons of lower energy than the original betas, which results in an alteration of the spectrum. Therefore, the spectrum is dependent upon the matrix and the distribution within the matrix. The energy spectrum available for detection is a continuum of scattered and unscattered electrons. The detected spectrum will depend on the characteristics of the detecting device. Gross beta detection is the recommended technique for measuring contamination.

Gross beta count rate can be used to detect an increase above the background beta count rate but cannot be used to identify specific radionuclides. Gross beta is usually only effective as a screening technique. The background count rate will depend on the efficiency of the device for beta and gamma, the volume and surface area of the device, and the device's field of view of the soil. The efficiency of most devices is nearly $100 \%$ for betas that reach the active detection volume; however, tritium and other low energy beta emitters cannot be detected by this method. Efficiency of the devices varies for gamma and depends on the detector material, shape, and volume. Gas detectors usually have a lower gamma efficiency than plastic detectors, so gas detectors are preferred for achieving a lower detection limit. Plastic detectors are generally much more robust for field applications and are the compromise of choice. Crystal-type detectors have thicker protective layers and hence, inactive layers that reduce beta sensitivity but have much higher gamma sensitivity than gas or plastic. Crystal detectors are not recommended because of the high gamma background and consequent high detection limit. Crystal detectors are necessary for bremsstrahlung detection; however, bremsstrahlung detection is investigated as a part of the gamma pulse height analysis test. 
Detector surface area is important to the sensitivity. The larger the surface area, the more the contaminant that is detected if the contaminant is uniformly distributed over an area greater than the detector surface area.

\subsubsection{Bremsstrahlung Radiation}

Another technique for detection of beta-emitting radionuclides relies on detection of bremsstrahlung radiation. Wheii betas are stopped by an atom, the energy can be converted to photons. These photons can be detected and analyzed by the same techniques as gamma rays. Bremsstrahlung production is inefficient, especially in low density materials such as soil. The production of bremsstrahlung photons can be approximated by Equation (4):

$$
f=3.5 \times 10^{-4} Z E
$$

where $\mathrm{f}$ is the fraction of betas converted to photons, $\mathrm{Z}$ is the atomic number of the absorber, and $E$ is the maximum energy of the beta spectrum in million electron volts. The following is an example of how little bremsstrahlung photons are produced.

A 2-MeV beta emitter that is present at $1,000 \mathrm{pCi} / \mathrm{g}$ in soil ( $Z$ approximately 10 ) would be expected to produce only the equivalent of $7 \mathrm{pCi} / \mathrm{g}$ of bremsstrahlung photons.

Also, the process produces a continuum of photons with the majority at low energy, and these low energy photons are poorly transported through the soil, thus making detection difficult.

Beta radiation from background radionuclides contributes bremsstrahlung radiation as does gamma radiation from background radionuclides and other contaminants. This gamma radiation produces degraded photons that contribute to the background in the bremsstrahlung region. Therefore, the bremsstrahlung technique is not expected to yield a low detection limit.

The distribution of the radionuclides is not important to beta detection because the technique is sensitive to a depth of $<0.5 \mathrm{~cm}$. Therefore, there is little error in assuming that the radionuclides are uniformly distributed throughout that depth of soil.

Bremsstrahlung radiation is detected using the gamma radiation detection equipment; therefore, no detection methods are described.

\subsubsection{Alpha Radiation}

The transuranic radionuclides, in particular plutonium-239, are alpha emitters (plutonium-239 and -240 are the only alpha emitters in the test site). The definitive method for measuring the concentration of these radionuclides is alpha spectrometry. 
Because alpha radiation has such a limited range in soil and air, background radiation is not a significant problem.

Alpha radiation in soil has an even smaller penetration depth than beta radiation; moisture and the matrix cause even larger interferences. Therefore, reliable soil concentration measurements of alpha-emitting radionuclides cannot be performed in situ. Other possible means of measuring alpha emitters are correlation to gamma or beta emitter concentrations, neutron detection, and gamma detection from the alpha emitters. Gamma detection of transuranics is described in Section 2.2.1.

The concentration of transuranic nuclides can be infirred from detectable radionuclides (such as gamma emitters) by correlating between the detectable nuclide and the transuranics of interest. To accomplish this, the technique relies on a number of assumptions, including the following:

- the detectable radionuclides have similar soil transport characteristics to the alpha emitters

- the radionuclides were released to the soil in nearly constant concentration ratios.

The time period of the releases must be small compared to the decay time of the detectable radionuclide or the differences in decay rates (the contaminants of this site have very long half lives). This prevents use of a single ratio because of the change in ratio during migration. Historical data do not support a correlation; however, the more complete data from this test may identify a ratio or set of ratios. The test in this case requires no additional measurements except laboratory radionuclide analysis of the alpha-emitting radionuclides. Correlations of detectable gamma emitters to alpha emitters are made after all the results are available.

\subsubsection{Neutron Radiation}

Spontaneous neutrons are emitted by the transuranics. This source of radiation may be useful in determining concentrations of transuranics in situ; however, it will not be specific for any radionuclide.

Background neutrons come primarily from the natural uranium series and cosmic radiation; however, the amount of neutrons from these sources is so low that they are considered insignificant.

The soil matrix can have significant effect on the transmission of neutrons. Water in the soil and the presence of any neutron absorbing materials, such as boron or cadmium, significantly restrict the transmission of neutrons. Other materials; like fluorine, give off neutrons after absorbing an alpha particle. Thus, the neutrons detected depend significantly on the sample matrix. 
The best neutron detectors available have detection limits of approximately

$1 \mathrm{nCi} / \mathrm{g}$. The concentration of neutron emitters in the 100 Area soils is in the pico curies per gram range. This is three orders of magnitude below the detection limit; therefore, neutron detection is not recommended.

\subsection{FIELD/LABORATORY NONRADIOACTIVE ANALYSIS CORRELATION}

Field screening techniques for nonradioactive contaminants are already being conducted as part of other Hanford investigations. Chromium is being addressed at the sodium dichromate expedited response action site and $\mathrm{x}$-ray fluorescence has been previously tested for metals on the Hanford Site.

While nonradioactive analysis correlation is not in the scope of this test plan, limited nonradioactive field screening is performed. During the excavation operations, a minimum of four samples are field screened for metals and organics. Should any of these show elevated levels of metals or organics, a sample will be sent to a laboratory for full analysis. These data will be compiled with data from the other Hanford investigations for use in determining a nonradioactive field/laboratory analysiș correlation.

\subsection{TEST PERFORMANCE AND DATA QUALITY OBJECTIVES}

\subsection{TEST PERFORMANCE}

\subsubsection{Dust Control}

The specific objective of the dust 'control test is to determine optimum systems for dust suppression during excavation activities. For purposes of the dust control test, "optimum" implies minimum use of dust suppression techniques while meeting regulatory requirements. Each component of the test program is described below.

3.1.1.1 No Dust Suppression--Perform excavation without any dust suppression measures to obtain baseline data for comparison with dust suppression results.

3.1.1.2 Water Spray--The water spray program is to assess the effectiveness of the standard water spraying methods used in remedial programs for dust control. The volume of water required to reduce the dust emissions to $<10 \mathrm{mg} / \mathrm{m}^{3}$ for total dust or $5 \mathrm{mg} / \mathrm{m}^{3}$ for respirable dust (dust particles <10 $\mathrm{m}$ in diameter) will be assessed (WAC 296-62-07509 and 07510).

3.1.1.3 Water With Additives--This test program compares the effectiveness of surfactant-laden water sprays to the effectiveness of plain water sprays. This test program is 
DOE/RL-93-04. Rev. 1

conducted in the same ranner as the water spray program for a direct comparison of results. This program assesses the volumes of water and surfactant required to reduce the dust emissions to $<10 \mathrm{mg} / \mathrm{m}^{3}$ for total dust or $5 \mathrm{mg} / \mathrm{m}^{3}$ for respirable dust.

3.1.1.4 Crusting Agents--Crusting agents are expected to be primarily effective during periods when the excavation activities are suspended. This test is performed during all parts of the testing program on the spoil piles. The objective of this test is to assess the application methods versus the effective duration of dust suppression.

\subsubsection{Field/Laboratory Radionuclide Analysis Correlation}

The objective of the field/laboratory radionuclide analysis correlation test is to gather field data of sufficient quantity and quality to allow comparison with laboratory analyses. The comparison allows development of calibration factors based un the following:

- in situ field of view

- soil density

- soil moisture content

- distribution of the radionuclides in the soil.

With this comparison, the in situ measu ement resuits can be used to determine optimum measirement parameters (counting time, field of view, and detector type and size) for achieving necersary measurement sensitivity anc detection limits. Initially. 10-minute counting times will be used for all detector systems. The counting time will be adjusted as neided during the test to determine the most efficient counting methodology. The number of samples required for a correlation will depend on the relative uncertainty of the measurements (which is a function of the counting time). One of the test objectives is to determine the minimum counting time required unjar varving circumstances to achieve the necessary relative uncertainty.

To minimize estimation error in field measurements. the detection limit should be a factor of 10 lower than the performance level (this is a widely used rule of thumb). Another test performance objective is. therefore, that sufficient information be aken for the in situ and laboratory measurements to allow development of measurement protocols that will ensure that in situ measurements have a detection limit that is $10 \%$ of the performance level. The objectives for each element of the test program are described.

3.1.2.1 Gamma Pulse Height Analysis Test. The test performance objective is to achieve a detection limit that is $10^{\%} \%$ of the performance level for cach gamma emitting radionuclide.

3.1.2.2 Gross Beta Test. The test performance objective is that the detection limit be $10 \%$ of the erformance level of the most restrictive radionuclide or $10 \%$ of the activity of the sum $\triangle 1$ the radionuclides that contribute 9()$\%$ of the total beta activity. These performance vejectives for either direct beta counning or bremsstrahlung are expected to be achieved only when the gamma contamination is near background. 
3.1.2.3 Gamma Detection from Transuranic Test. The test performance objective is to achieve a detection limit for americium-241 that will represent $10 \%$ of the plutonium-239 performance level. These performance objectives are expected to be achieved only when the gamma contamination is near background.

3.1.2.4 Bremsstrahlung from Gamma Spectra Test. The test performance objective is to achieve a detection limit for strontium-90 that is $10 \%$ of the strontium-90 performance level.

\subsection{COMPARISON LEVELS}

The test results are compared against the performance levels listed in Table $1-1$ and the potential requirements and cleanup standards listed in Table 3-1.

\subsection{DATA QUALITY OBJECTIVES}

Datá quality objectives (DQO) are baseud on data quality needs. The implementation of an appropriate quality assurance/quality control (QA/QC) program is required to ensure that data of known and documented quality are generated. The DQO define the level of QA/QC for the treatability testing and analysis. The DQO for this remedy selection and design are quantitative in nature for the following reasons:

- The field/laboratory radionuclide analysis correlation must relate specific field analytical results to the radionuclide levels determined by laboratory analysis. These results are used to ensure that specific performance criteria for radionuclide concentrations in soil are met.

- The dust suppression measures must meet specific performance criteria (i.e., total and nuisance dust levels).

DQO analytical levels a:: defined in EPA's Guide for Conducting Treatability Studies Under CERCLA (EPA 1989). This guide states that the requisite analytical levels are dictated by the types and magnitudes of decisions to be made based on the data and the objectives of the test. This treatability study covers monitoring of a remedial action (excavation): therefore, the tests performed for this study generally involve field screening or analysis procedures. Some sample analyses will be performed using standard laboratory procedures to generate the lield/laboratory correlation and for QA/QC. The analytical levels appropriate for monitoring remedial actions are levels I. II, and III (EPA 1987. Table 4-4); however. these levels only apply to chemical analysis. To address radiological samples (technically analytical level $V$--other analysis), the following analytical levels are defined. These levels are essentially identical to the definitions for analytical levels I, II, and III; however, these refer to radiological analysis. 
- Level A, field screening or analyses usine portable instruments. Results are often not compound-specific or quantitative but are available in real-time.

- Level B, field analyses using more sophisticated portable analytical instruments. In some cases, the instruments may be set up in a mobile laboratory onsite. The quality of data generated depends on the use of suitable calibration standards, $i$ aference materials, sample preparation equipment, and the training of the operator. Results are available in real-time or several hours.

- Level C, all analyses performed in an analytical laboratory.

Table 3-1. Potential Requirements and Cleanup Standards for Comparison of the Excavation Treatability Test Results.

\begin{tabular}{|c|c|}
\hline Regulation & Citation \\
\hline \multicolumn{2}{|l|}{ FEDERAL } \\
\hline Residual Radionactivity levels & $\begin{array}{l}\text { RISRAD2. Atomic Energy Act of } 1954 . \\
\text { as amended. 20 CIR } 960.962\end{array}$ \\
\hline Radiation Protection Standards & 4) CIR Pan 191 \\
\hline $\begin{array}{l}\text { U.S. Nuclear Regulatory Commission (NRC) Standards for Protection Against } \\
\text { Radiation }\end{array}$ & 10 CFR P'art 20 \\
\hline National Primary and Secondary Ambient Air Quality Standards & 4 (1) CIR Part 50) \\
\hline National Emissions Standards for Hazardous Air Pollutants & 4) ClR l'arn 61 \\
\hline Radiation Protection for (Jecupational Workers & DOE: 5480.11 \\
\hline Radioactive Waste Management & DOOE $5820.2 \mathrm{~A}$ \\
\hline Residual Radioactive Material as Surtace Contamination & NRC Guide 1.86 \\
\hline Radiation Protection of the Public and the Environment & D)( I: 5400.5 \\
\hline \multicolumn{2}{|l|}{ STATE } \\
\hline $\begin{array}{l}\text { Benton-Franklin-Walla Walka Countes Air l'illutu'n } \\
\text { Control Authority }\end{array}$ & Genteral Rey. 801-? \\
\hline Air Pollution Requirements & WAC $172-300$ \\
\hline Nuisance Dusts & WAC 296.62 .0175014 \\
\hline Total Particulate & WAC 296-62-(1)7510 \\
\hline Emission Limits lor Radionuclides & W.AC $173-480$ \\
\hline
\end{tabular}

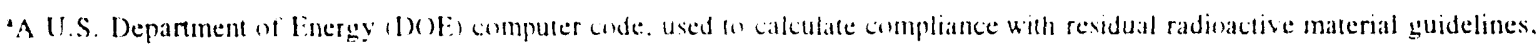
developed at the Environmental Assessment and informatun Sciences Divison or Argune National Laboratory. Illinois.

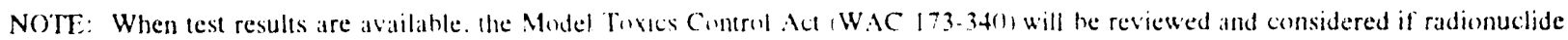
standards have heen promulgated. 
To ensure that the correct level of detail and data quality are achieved for evaluating field/laboratory radionuclide analysis correlation and dust control. DQO tables are prepared based on the guidance given in Data Quality Objectives for Remedial Response Activities (Development Process) (EPA 1987). To define DQO, the following information is required (EPA 1987):

- primary data users

- data use

- analytical levels

- contaminants and levels of concern

- critical samples

- required detection limits.

The primary data users for this project include:

- DOE, EPA, and Washington State Department of Ecology (Ecology) remedial project managers

- DOE, EPA, and Ecology unit managers

- Westinghouse Hanford Company (WHC) RI and FS coordinators.

Tables 3-2 to 3-8 present the remaining DQO information. These tables list the following:

- test objectives

- prioritized data uses

- appropriate analytical levels

- target analytes for the test

- level of concern for each analyte (if any)

- critical samples for the test (if any).

Additionally, the required detection limits are provided in the test contractor's test procedures. The contaminants of concern are listed in Table $1-1$ along with their respective level of concern (i.e., performance level). Test data will be of sufficient quality and type to satisfy the test objectives listed in Section 3.1. 
DOE/RL-93-04, Rev. 1

Table 3-2. Data Quality Objectives for the Excavation Treatability Test Plan Dust Control--Baseline.

\begin{tabular}{|c|c|c|c|c|c|c|}
\hline & \multirow{4}{*}{ 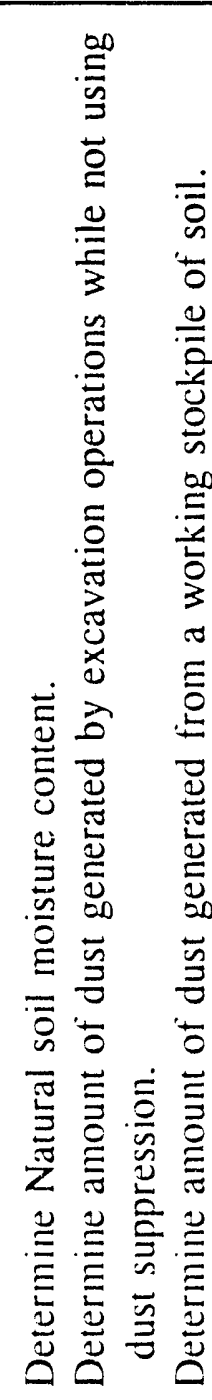 } & \multirow{4}{*}{ 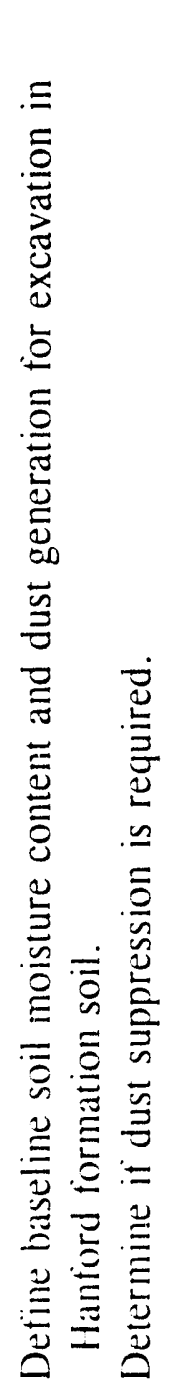 } & \multirow[b]{4}{*}{$<$} & \multirow{2}{*}{ 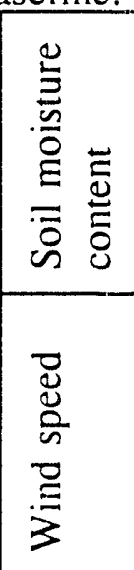 } & 产 & \\
\hline & & & & & $\begin{array}{l}\overline{\bar{a}} \\
\stackrel{\Xi}{ } \\
\underline{\underline{n}}\end{array}$ & \\
\hline & & & & 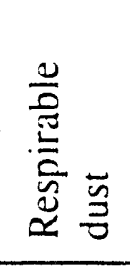 & $\begin{array}{l}\mathfrak{E} \\
\hat{E} \\
\Xi \\
n \\
\end{array}$ & \\
\hline 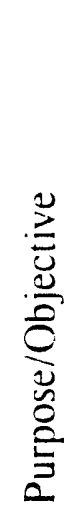 & & & & $\frac{\overline{\breve{s}}}{\frac{3}{3}}$ & 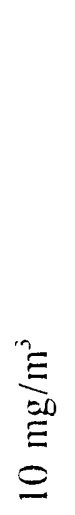 & $\begin{array}{l}\mathscr{0} \\
\stackrel{0}{z}\end{array}$ \\
\hline ن & 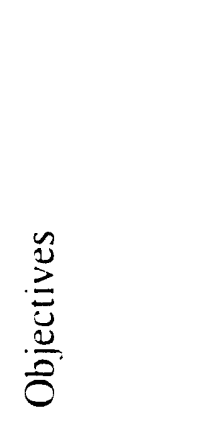 & 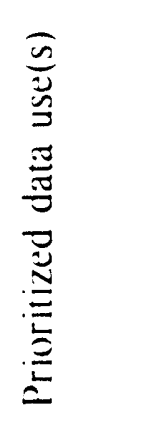 & 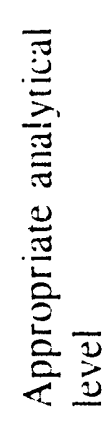 & 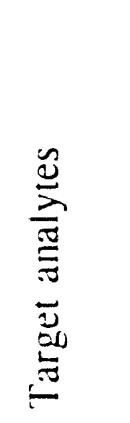 & 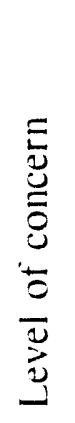 & 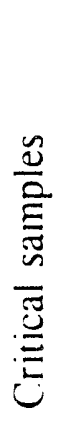 \\
\hline
\end{tabular}


DOE/RL-93-04, Rev. 1

Table 3-3. Data Quality Objectives for the Excavation Treatability Test Plan Dust Control--Water Sprays.

\begin{tabular}{|c|c|c|c|c|c|c|c|}
\hline \multirow{6}{*}{ 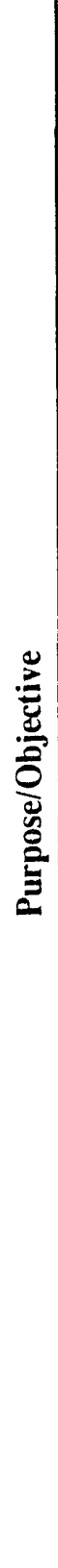 } & \multirow{6}{*}{ 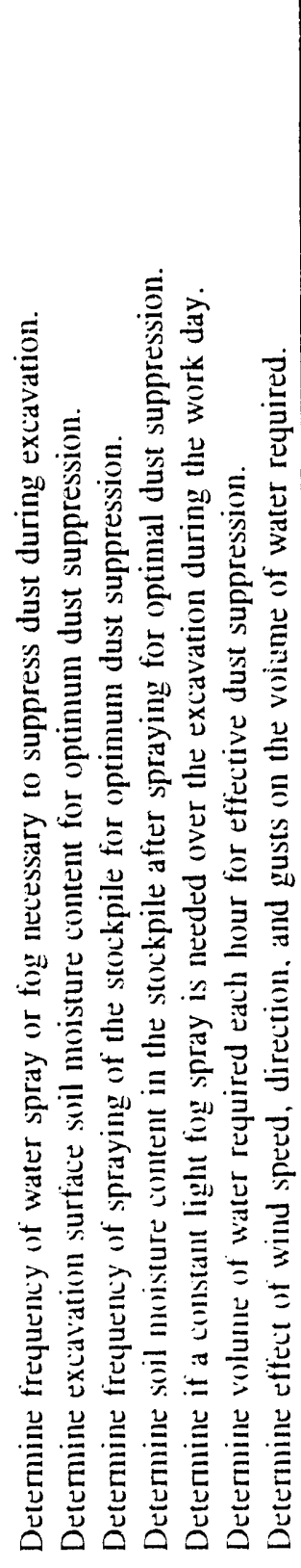 } & \multirow{6}{*}{ 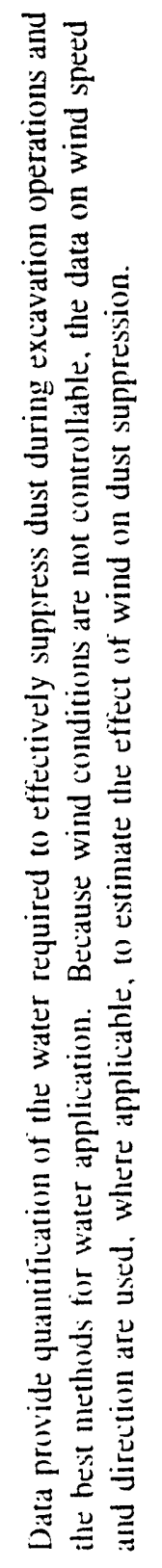 } & \multirow{6}{*}{ 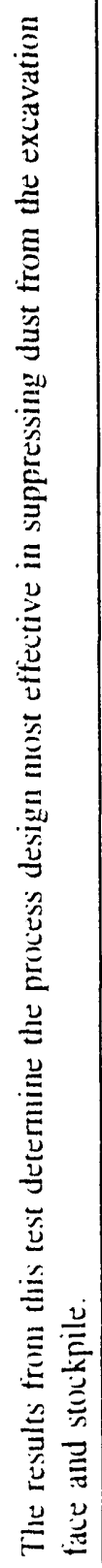 } & & 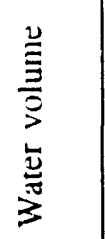 & $\stackrel{\underline{Z}}{E}$ & \\
\hline & & & & & 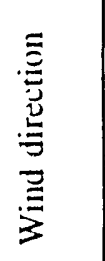 & $\stackrel{\text { L }}{\bar{z}}$ & \\
\hline & & & & & 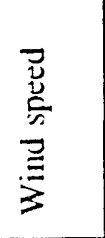 & $\begin{array}{l}\overline{\bar{\Xi}} \\
\underline{\Xi}\end{array}$ & \\
\hline & & & & & 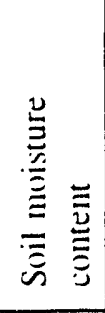 & $\stackrel{\underline{\underline{E}}}{\bar{z}}$ & \\
\hline & & & & & 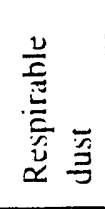 & 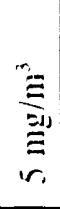 & \\
\hline & & & & & $\frac{\overrightarrow{3}}{\overrightarrow{3}}$ & $\begin{array}{l}\hat{\Xi} \\
\underline{\Xi} \\
\underline{\Xi}\end{array}$ & $\stackrel{\text { }}{\underline{\Sigma}}$ \\
\hline 蓄 & : & 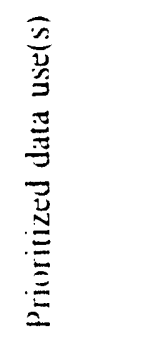 & & 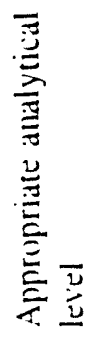 & 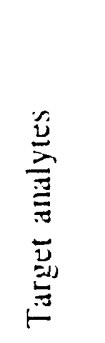 & 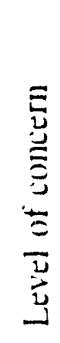 & 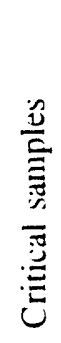 \\
\hline
\end{tabular}


Table 304. Data Quality Objectives for the Excavation Treatability Test Plan Dust Control--Water with Additives.

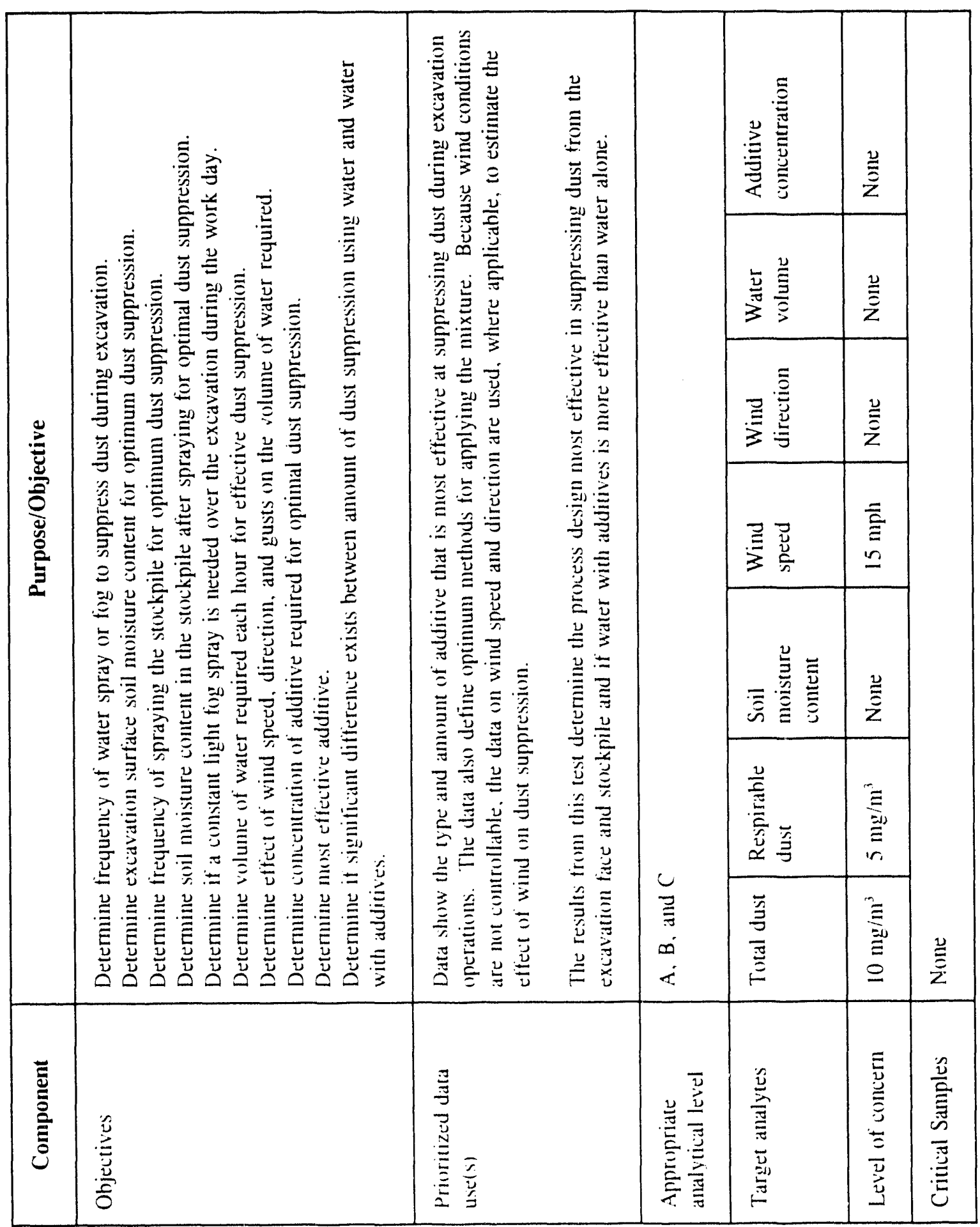


Table 3-5. Data Quality Objectives for the Excavation Treatability Test Plan Dust Control--Crusting Agents.

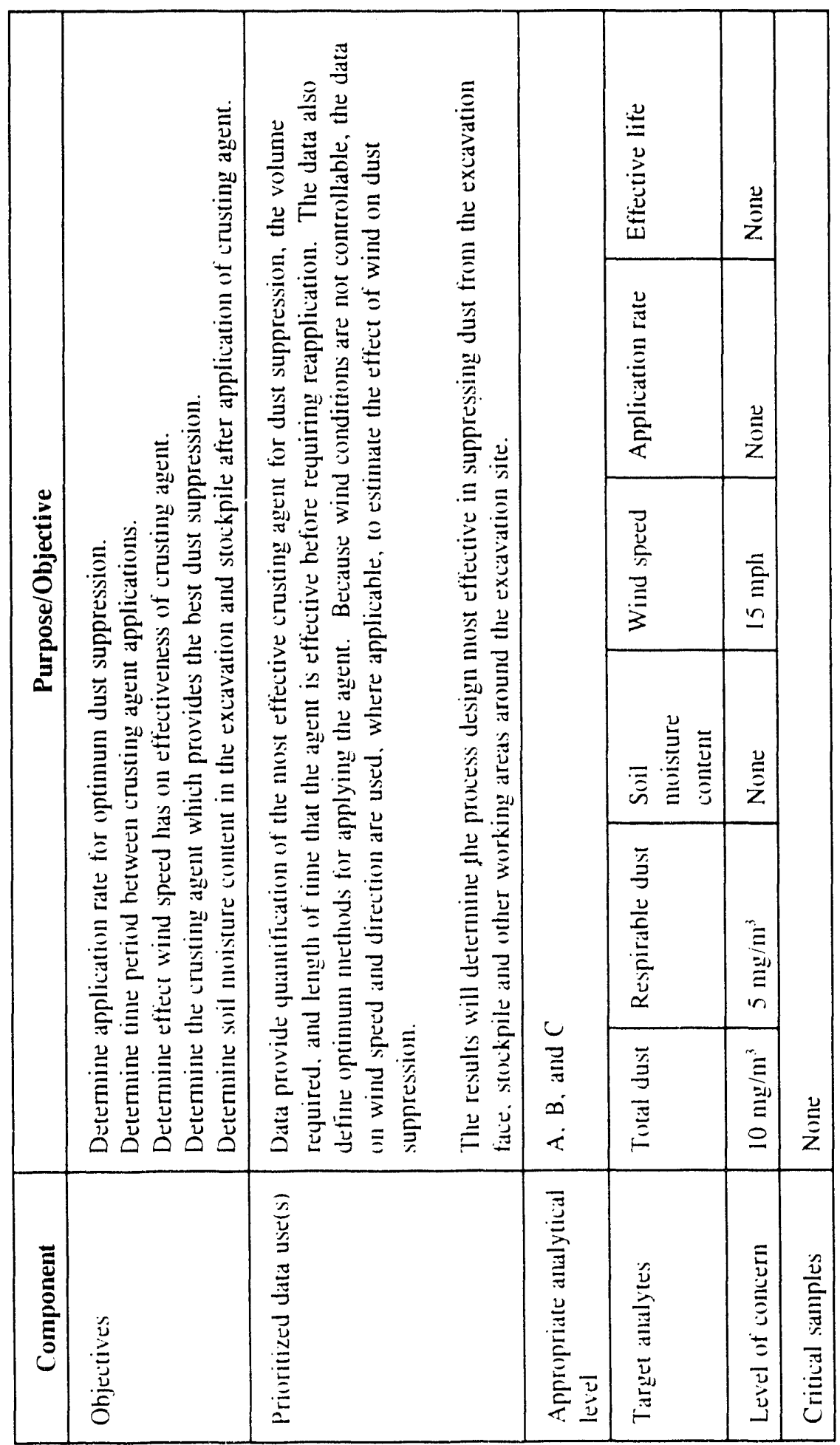


Table 3-6. Data Quality Objectives for the Excavation Treatability Test Plan Field/Laboratory Radionuclide Analysis Correlation--Gamma Pulse Height Analysis.

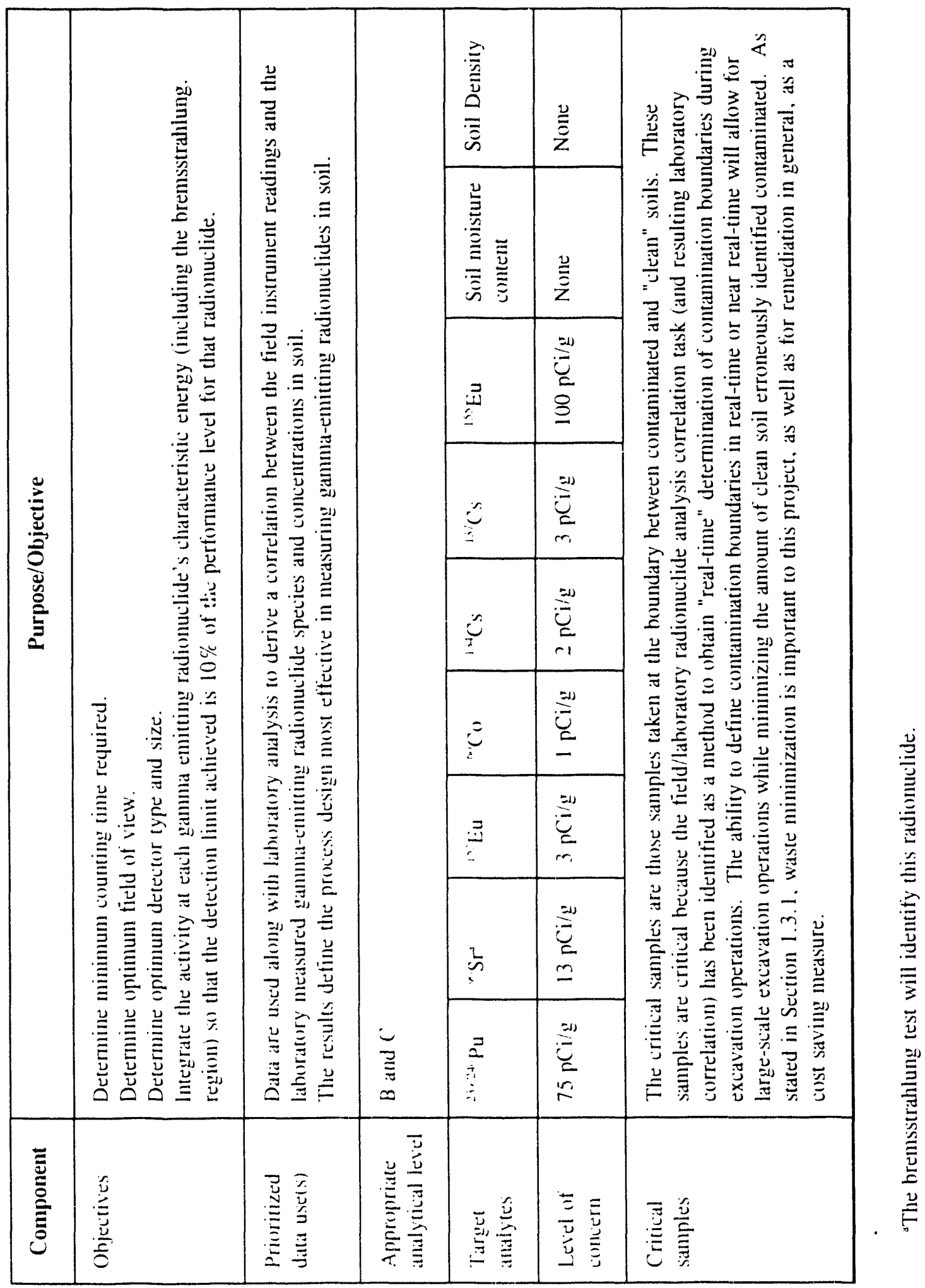


Table 3-7. Data Quality Objectives for the Excavation Treatability Test Plan Field/Laboratory Radionuclide Analysis Correlation--Gross Beta Test.

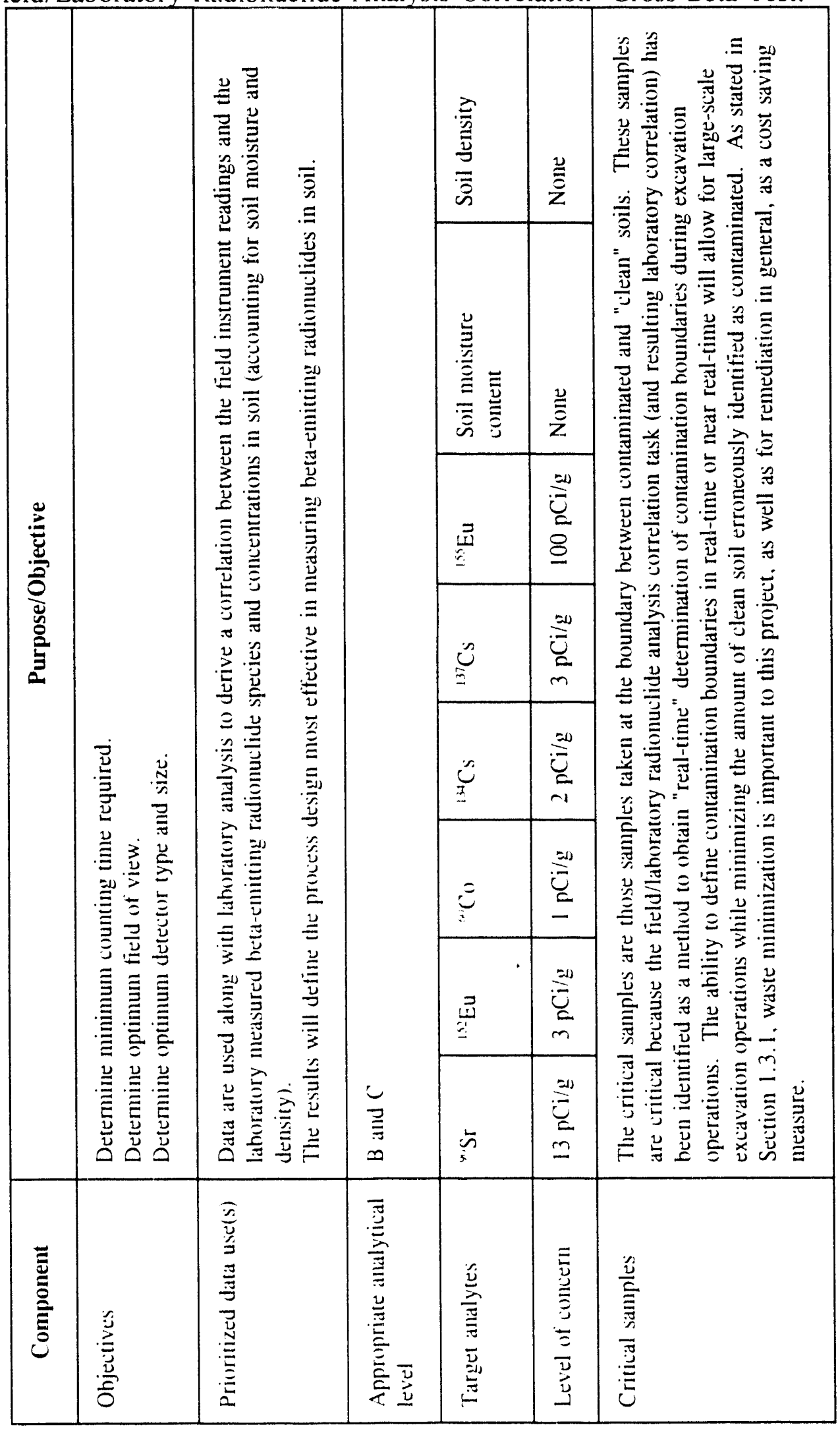


Table 3-8. Data Quality Objectives for the Excavation Treatability Test Plan Field/Laboratory Radionuclide Analysis Correlation--Gamma Detection from Transuranics.

\begin{tabular}{|c|c|c|c|c|c|c|}
\hline \multirow{4}{*}{ 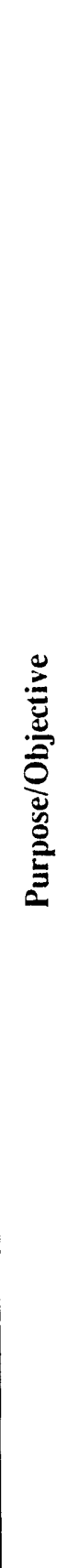 } & 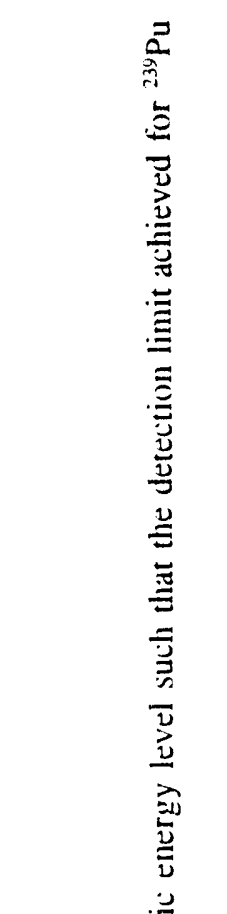 & 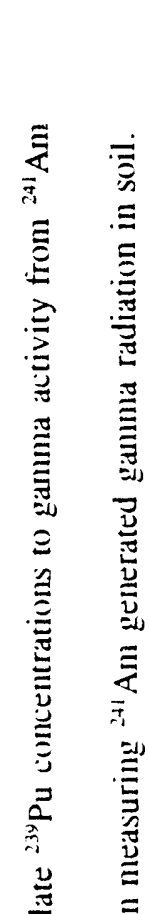 & & 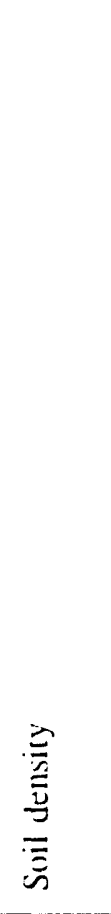 & 兰 & 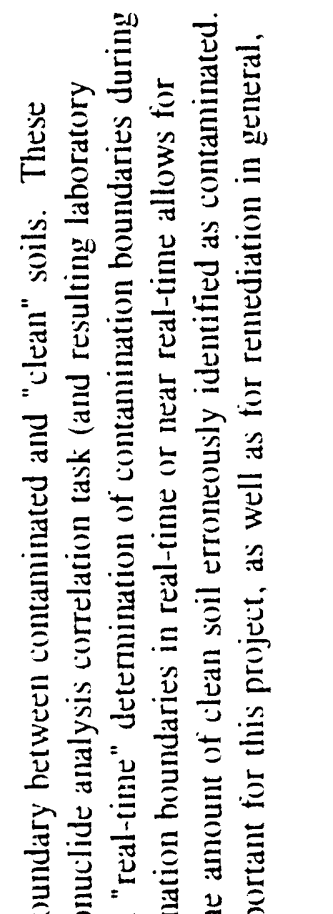 \\
\hline & 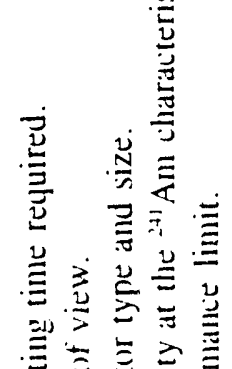 & 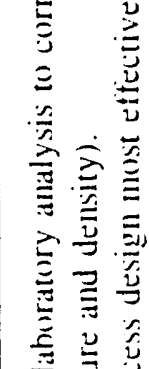 & & 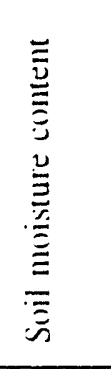 & 岂 & 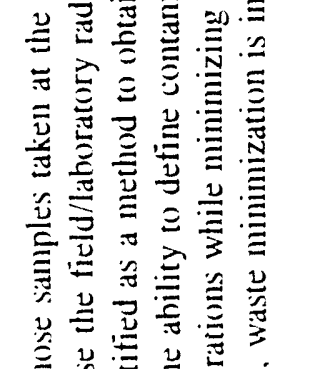 \\
\hline & 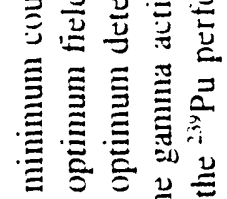 & 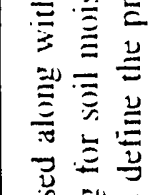 & & $\stackrel{2}{2}$ & 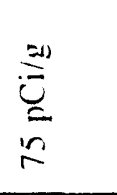 & 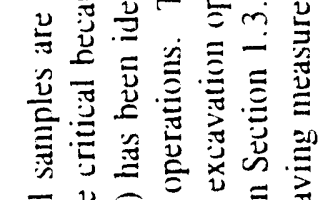 \\
\hline & 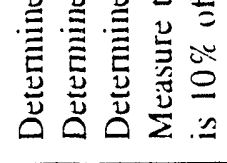 & 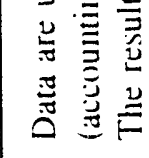 & 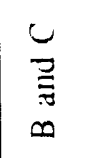 & $\underset{\bar{X}}{\bar{X}}$ & 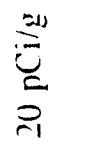 & 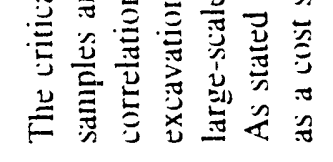 \\
\hline 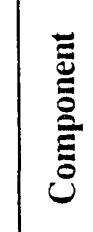 & 竧 & 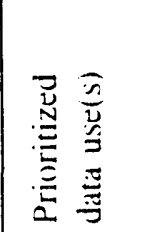 & 竞 & 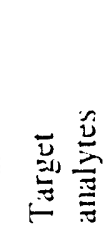 & 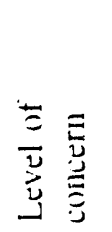 & 焉食 \\
\hline
\end{tabular}


DOE/RL-93-04, Rev. I

\subsection{EXCAVATION TREATABILITY TEST EXPERIMENTAL DESIGN AND SPECIFICATION}

\subsection{DUST CONTROL EXPERIMENTAL DESIGN}

\subsubsection{Overview of the Test Program}

Soil is excavated from the site in approximately 2-ft lifts using a backhoe. Contaminated soil (based on field analysis and performance levels) is placed in the contaminated soil storage area. Uncontaminated soil (based on field analysis and performance levels) is placed in a staging area established near the excavation. The soil in the staging area is moved to the clean soil stockpile after the next lift has been analyzed. Any material designated as unconaminated that overlies contaminated soil is analyzed further before movement to the clean sril stockpile. After the excavation is completed, the uncontaminated soil is used as backfill for the site.

The site preparation phase includes the following:

- designation of the clean soil stockpile area, and construction of the contaminated soil storage area and staging area

- delineation of the excavation site into exclusion, contamination reduction, and support zones.

Once excavation begins, soil determined to be uncontaminated based on the in-place radiation monitoring, is placed in the clean soil stockpile. Material determined to exceed performance levels is placed in the contaminated soil storage area. The excavation side walls are sloped a minimum of $0.5: 1$; however, the side slope angles may be increased if required to maintain stability of the excavation or for personnel access. Personnel will not enter the excavation unless the side walls are sloped at least 1.5:1. The excavation proceeds down to the bottom of the crib, then continues until two clean lifts have been removed after the last contaminated lift, or to a maximum depth below land surface of $25 \mathrm{ft}$. Should the contamination extend further laterally than expected, the excavation test can be readdressed to determine how to handle the problem, including assessing the added storage volumes required. The sampling strategy outlined in Appendix A includes discretionary samples for each lift. These samples can be used to analyze areas of local change in soil type or other anomalies.

During the excavation, finur dust suppression programs are tested:

- Ground surface samples for total dust are collected upwind and downwind from the excavation, the staging area, the clean soil stockpile, and the contaminnted soil storage area. 
- Real-time dust levels are measured around the excavation including all storage areas.

- Personal total dust samples are also collected for the equipment operator and ground crew.

- Soil moisture content is measured in the excavation, clean soil stockpile, and contaminated soil storage area to determine the optimum moisture content for dust suppression for each phase of the testing program.

Once the excavation is completed, and the remaining soil in the excavation site is shown to meet the performance limits, the uncontaminated soil may be replaced in the excavation and compacted. The decision to backfill the excavation is made after the test is complete and the data reviewed. Soil exceeding performance criteria remains in the contaminated soil storage area for possible later use during additional treatability tests (such as soil washing).

All excavation and testing are performed by WHC or their designee. Details of the excavation and associated test programs are discussed in the subsections below.

\subsubsection{Site Layout}

Exclusion, contamination reduction, and support zones are described as follows:

- Exclusion zone - Includes the entire excavation area and staging area, plus additional area(s) required for equipment movement and personnel work space.

- Contamination reduction zone - Includes the equipment and personnel decontamination area.

- Support zone - Includes the office trailer, support facilities, and all other areas used for this project.

Access to the exclusion zone is strictly controlled and restricted to authorized personnel having completed hazardous waste worker training according to 40 Code of Federal Regulations 1910.120 and Washington Administrative Code 296-62-3040 as well as radiation worker training and other site specific training as required. A log of all persons entering the exclusion zone is maintained.

\subsubsection{Site Preparation}

Prior to the start of the excavation, the area is prepared by designating the clean soil stockpile area, and constructing the contaminated soil storage unit and staging area. The existing security fence is temporarily dismantled. where necessary, to accommodate 
excavation activities. The contaminated soil storage unit is designed to hold the maximum volume of contaminated soil to be excavated, an estimated $500 \mathrm{yd}^{3}$.

The staging area is located within reach of the backhoe bucket and is positioned a minimum of $10 \mathrm{ft}$ from the edge of the excavation. The staging area is prepared by grading to remove any debris that may penetrate the plastic sheeting and placing several layers of reinforced-plastic sheeting over the prepared area. The plastic is weighted around the perimeter with clean fill. The contaminated soil storage unit is constructed according to manufacturer's instructions.

To minimize the waste volume generated, the backhoe bucket is decontaminated, (when needed as indicated by field screening) over the contaminated soil removed from the site. This allows the water to absorb into the soil designated for placement in the contaminated soil storage unit. The entire backhoe is decontaminated onsite prior to demobilization (if required). Decontamination operations are performed according to $\mathrm{WHC}$ procedures applicable at the time of the test.

\subsubsection{Test Excavation}

The crib area to be excavated is estimated at 10 by $10 \mathrm{ft}$ in plan view; the contamination is estimated to extend over a 20 by $20 \mathrm{ft}$ area to a depth of $25 \mathrm{ft}$. The excavation begins at one side of the crib area and is performed in 2-ft lifts. After a lift is removed, the sampling locations are prepared by leveling and tamping with the backhoe bucket. The sample locations for each lift are accurately located by survey or other methods. Then, the soil in the bottom of the excavation is tested using the in situ field radiation instrumentation. After the in situ radiation samples, grab samples of the surface soil in the excavation are obtained. Once the instrument readings and samples are obtained and analyzed. the contaminated area is marked and recorded in the field logbook, and the next soil lift is excavated.

\subsubsection{Dust Suppression Test Program}

During the test excavation. dust may be generated at the following locations:

- walls and base of the excavation

- backhoe bucket during digging and soil movement

- clean soil stockpile

- contaminated soil storage unit

- staging area.

The dust suppression test program is designed to assess the effectiveness of each method for each of these areas and is separated into the following four phases of field testing.

4.1.5.1 General Test Conditions. Throughout the duration of the test programs, continuous readings of the meteorological conditions are collected using a meteorological 
station. The meteorological station records wind speed. wind direction. temperature. barometric pressure, and relative humidity.

Dust samples are collected from totalizing air samplers located in the exclusion area and support zone, from a real-time portable monitor, and from personal air samplers. The sample locations and frequencies are described in the test procedures provided by WHC.

Moisture content testing of the soil in the excavation, staging, and stockpile areas is performed throughout the test program. Grab samples are collected at the soil depths and locations required by the test contractor and analyzed.

4.1.5.2 Phase 1--No Water Addition. This phase of the test program is performed at the start of the excavation. The objective is to obtain baseline dust measurements during excavation conducted without any form of dust suppression.

4.1.5.3 Phase 2--Water Spray. The objective of this phase is to assess the effectiveness of the standard method of water spraying fir dust control during construction or remediation projectis.

Water spraying or fogging is performed using portable, standard fog-spray nozzles typically used in construction (selection of nozzle type is left to the test contractor). Fog spraying is performed over the excavation cut surfaces and during movement of soil. Dust measurements are taken during the excavation activities as described in the test contractor's procedures. Fog spraying of the potential dust generation locations is conducted on an asneeded basis. The objective is to use the minimum amount of water to meet dust control requirements as measured by real-time dust monitoring and visual observations. Real-time dust measurements are performed as specified in the test plan. Additional agents for dust suppression are added as indicatec by air monitoring results or visual observations.

During the fog spraying, accurate records are maintained for the volume of water uitized each hour for dust suppression. the number of times each area was fog sprayed. and the duration of each spraying episode. Visual observations on the effectiveness of fog' spraying are also recorded.

is each lift is excavated. surveved. and sampled. the newly exposed surface is fog sprayed for dust suppression. and soil moisture samples are collected for testing as described in the test contractor's procedures. Similarly. soi! moisture content samples are collected in the clean soil stockpile and staging area following fog spraying.

4.1.5.4 Phase 3--Water With Additives. This test phase replicates the work of the Phase 2 program: however. the effectiveness of adding surfactants to the water is assessed. Two primary surfactants are tested. The wo surfactants chosen are EMC Squared H2O+. manufactured by Soil Stabilization Products (o. Inc.. Merced. California. and MSDC. manutactured by Pico Chemical Corporation. Tinley Park. Illinois. 
The water/surfactant mixtures are prepared according to the manufacturer's directions, and applied using standard, portable fog-spray nozzles. Fog spraying is performed as specified in Phase 2.

During the fog spraying, accurate records are maintained for the volume of water utilized for dust suppression, the concentration/volume of surfactant used, the number of times each area was fog sprayed, and the duration of each spraying episode. Visual observations on the effectiveness of fog spraying are also recorded. Surfactant/water dilution ratios may vary over the testing period. Detailed records of the dilution ratio, volume of water/surfactant applied, application frequency, results of the real-time dust monitoring, and visual observations are maintained for each surfactant/water mixture.

As each lift is excavated, surveyed, and sampled, the newly exposed surface is fog sprayed for dust suppression. Samples for soil moisture content determination are collected for testing as described in the test contractor's procedures. Similarly, the soil moisture content samples are collected in the clean soil stockpile and staging area following fog spraying.

4.1.5.5 Phase 4--Crusting Agents. Crusting agents are tested over periods between operations, i.e., overnight and over weekends. However, no crusting agents are used during Phase 1 tests (no dust suppression). Crusting agents are tested throughout the remaining excavation operation (Phases 2 and 3). Three crusting agents are selected for testing. Crusting agents are chosen from the search of available products and include:

- Coherex (or equivalent nonpetroleum-based crusting agent), manufactured by Witco, Golden Bear Division, Chandler, Arizona

- Soil Seal, distributed by Soil Stabilization Products Co. Inc.,

- Lignosite Road Binder manufactured by Georgia-Pacific Corporation, Bellingham. Washington.

NOTE: Winds $<5$ mph may restrict field operations.

At the end of the working day. final dust level measurements are taken as described in the test procedures. If dust measurements or visual observations indicate allowable dust levels are being i rctoded on site, additional crusting agent may be applied. Any additional applications of crusting agent are recorded in the field logbook.

Prior to the start of work the following day. real-time dust measurements are taken at the designated locations in the exclusion area. The filters are collected from the totalizing air samplers and replaced.

During the application of the crusting agent solution, accurate records of the volume of water applied. volume of crusting agent applied. number of applications, and time of 
application are kept. Following application of the crusting agent solution, the soil moisture content is measured in the excavation and in the clean soil stockpile.

\subsubsection{Backfilling and Compaction}

The disposition of the excavated soil is based on the results of the in situ gamma detection using the extended-range germanium detector and confirmatory laboratory samples of the soil pile.

Completion of the following steps to abandon the test pit is protective of groundwater and constitutes a variance from WAC-173-360. In accordance with direction from Ecology, no additional variance will be required for test pit abandonment. Excavated soil with contamination levels below performance levels may be replaced in the excavation in lifts and compacted by tamping with the backhoe bucket. If required, clean imported soil from a Hanford borrow site will be used to make up the volume, if necessary. During backfilling, the upper $6 \mathrm{ft}$ of the excavation is compacted in 18-in. lifts using the backhoe.

A final site surface survey is performed to monitor radiation levels; any surface areas determined to exceed performance levels are removed and transported to the contaminated soil storage unit. Material placed in the contaminated soil storage unit is securely covered and stored for possible future use in other treatability tests (such as the soil washing test program).

\subsection{FIELD/LABORATORY RADIONUCLIDE ANALYSIS CORRELATION EXPERIMENTAL DESIGN}

Field measurements of soil radionuclides are made after each excavation lift. During each measurement campaign, detectors are placed at the locations indicated in the test contractor's procedures and left in place for the required counting time. Afterwards, they are removed and a composite soil sample from the area of view under each detector is collected. Three tests are performed at each sample location: gamma pulse height analysis, gross beta, and gamma from transuranics. These measurements detect all of the contaminant radionuclides present in the test site. The following subsections provide test details.

\subsubsection{Overview of the Test Program}

Field radiation measurements are performed at each point indicated in Appendix A. The instruments are used to perform the following tests:

- Gamma pulse height analysis for gamma emitters, correlation to americium-241, and bremsstrahlung radiation measurements

- Large-area beta measurements for gross beta activity. 
After the required counting time, the results are reviewed by the excavation team, and, based on the levels of radionuclides measured and performance limits, the area is designated as either contaminated or clean. Sites designated as contaminated are marked to help the field crew identify the area of contamination to be excavated in the next list. After the radiation measurements are completed, a sample is taken of the top few inches of soil from the field of view of the instruments.

\subsubsection{Gamma Pulse Height Analysis Test}

For each lift of the excavation, gamma pulse height analysis readings are made at each sample location. These readings utilize both ratio and region of interest modes, using the $\mathrm{NaI}$ detector with single channel and multichannel analysis, or the germanium $(\mathrm{Ge})$ detector using multichannel analysis (necessary because of the higher resolution). The readings, ratios, and spectral analyses are compared to gross gamma from the $\mathrm{NaI}$ detectors to determine those cases where gross gamma is an adequate screening method.

\subsubsection{Gross Beta Test}

For each lift of the excavation, gross beta readings are taken by integrating the counts at each sample location for the required counting time. Bremsstrahlung measurements for gross beta result from the gamma pulse height analysis test.

\subsubsection{Gamma Detection from Transuranic Test}

The gamma test for transuranics examines the gamma activity at the characteristic energy of americium-241 (60 keV). This test is essentially identical to the gamma pulse height analysis, using an extended range germanium detector, and is performed as part of the gamma pulse height test.

\subsection{EQUIPMENT AND MATERIAL}

\subsection{FIELD/LABORATORY RADIONUCLIDE ANALYSIS CORRELATION}

Equipment required for analysis correlation comprises:

- Gamma pulse height instrument with spectral storage media for at least 20 spectra is recommended to perform the analysis after all locations have been sampled. A 2,000-channel multichannel analyzer is sufficient for sodium iodide, but a 4,000-channel system should be used for germanium. One analyzer could be 
used for both, but requires adjustment and calibration when switching from one type detector to the other. The largest possible germanium detector with the highest efficiency is recommended.

- Large area beta instrument.

Material will consist of sample containers and appropriate sampling equipment.

\subsection{DUST CONTROL}

A variety of equipment and materials are used for the dust control test program. The following is a list of major equipment and materials:

- Equipment<smiles>[3H][AlH2]</smiles>

- backhoe - CAT 245 trackhoe or equivalent

- water truck or local source of water

- totalizing ambient air samplers

- generators and air compressors

- meteorological station for wind speed/wind direction, temperature, relative humidity, and barometric pressure

- personal air samplers

- liquid flowmeter and totalizer

- automated, real-time dust monitor

- 2-way radios.

- Material

- personal sampler filter material and filter housings

- totalizing air sampler filters obtained from laboratory performing gravimetric testing

- clean fill

- plastic sheeting

- 55-gal drums

- fog spray nozzles

- various dust control agents.

\subsection{SUPPORTING DOCUMENTATION}

Much of the supporting documentation for this test plan is included in the 100-FR-1 Operable Unit RI/FS work plan (DOE-RL 1992d). While the work plan primarily covers the RI Phase I investigation, much of the supporting documentation is applicable to treatability testing as well. Supporting documents in the work plans include a field sampling plan, a quality assurance project plan (QAPjP), a health and safety plan, and a data management plan (called the information management overview). The data management plan is 
supplemented by Environmental Investigation Instruction (EII) 14.1. "Analytical Laboratory Data Management" (WHC 1988). These supporting plans are applicable to all work scope performed by WHC.

Treatability test-specific procedures and sampling procedures are prepared for the excavation treatability tests by WHC. These documents use the work plan version as a basis for plan development with test-specific modifications as necessary. All work performed on the Hanford Site follows the site-specific QAPjP and procedures, although these may need to be modified to include test-specific requirements. The treatability test-specific procedures specify the methods and procedures used and DQO to ensure consistency. The QAPJP meets the requirements of the Environmental Engineering, Technologv, and Permitting Function Quality Assurance Program Plan (WHC 1990).

Community relations are performed in accordance with the Tri-Party Agreement, Section 10 (Ecology et al. 1989). Information regarding this study are likely disseminated during the quarterly public information meetings. WHC will prepare a hazardous waste operations permit, radiation work permit, and safety analysis plan prior to initiation of field activities. All activities are performed as specified in these documents.

\subsection{RESIDUALS MANAGEMENT}

This treatability test does not involve treatment of contaminated material; therefore, the only residual products from the test are the soil excavated from the site, soil samples from the excavation, and protective clothing and other materials contaminated by the soil. The soil may contain small amounts of dust suppressants and fixants used during excavation. Suppressants and fixants include water, water with surfactants, and crusting agents. The soil is sampled and analyzed as Section + and Appendix A specify. The soil that is identified as noncontaminated is returned to the excavation as backfill. The soil that is contaminated, and therefore regulated by DOE, remains in the contaminated soil storage unit on the test site until needed for future processing. Protective clothing and other materials are handled along with the soil that contaminates it. WHC is responsible for managing all waste material generated by this test. Specific EII (WHC 1988) applicable to this test are:

- EII 4.3, "Control of CERCLA and Other Past-Practice Investigation Derived Waste"--establishes a system to control the containment, labeling, and tracking of waste generated during Comprehensive Environmental Response, Compensation, and Liability Act of 1980 and other past-practice waste site environmental investigations, site characterizations. and well maintenance activities.

- EII 4.4. "Control and Storage of Radioactive Materials and Equipment"--provides the methods io meet requirements for control and storage of radioactive materials and applies to radioactive materials generated during operations managed by WHC. 


\subsection{REPORTS}

A report is issued following completion of the field tests and documents the results of the field/laboratory radionuclide analysis correlation and dust control tests. This report includes the following, at a minimum.

- Detailed description of the dust control systems tested (including equipment and procedures) and the results of each test.

- Recommended dust control system for use during remediation.

- Detailed description of the field/laboratory radionuclide analysis correlation test and the resulting correlation between field and laboratory analyses.

- Recommended future tests for full-scale implementation of dust control and field/laboratory radionuclide analysis correlation systems.

- Data evaluation and interpretation to show comparison of test results with expected performance and with performance standards in Section 1.3.

- Assessment of overall adequacy of the total measurement system with regard to the DQO of the investigation.

- Data package (including data summary sheets) and QA documentation for each test.

A suggested outline for the report is given in the Guide for Conducting Treatability Studies Under CERCLA (EPA 1989).

\section{1) SCHEDULE}

Figure 9-1 presents the schedule for planning and performing excavation treatability tests. The treatability test field activities will be completed by November 1993.

The execution of this treatability tesi may produce to $500 \mathrm{yd}^{3}$ of contaminated soil that will be used for future treatability tests. Test tests may include soil washing with vitrification of the soil washing residuals. Figure 9-2 presents a proposed integrated schedule for the ongoing and future treatability tests. This schedule will be refined once data are available from the ongoing bench-scale soil washing tesis. 
DOE/RL-93-04, Rev. 1

Figure 9-1. 100-Area Excavation Treatability Test Schedule.

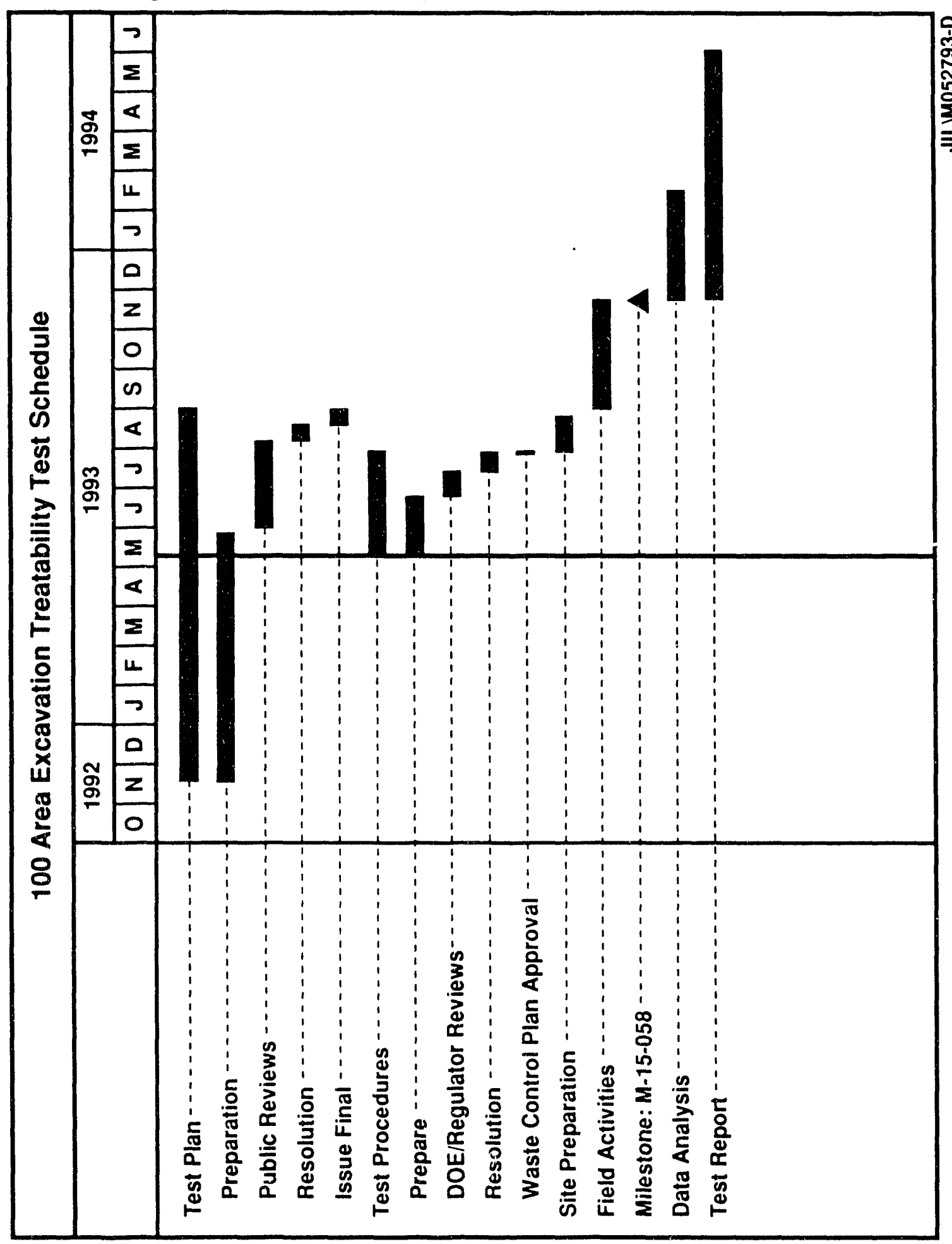


Figure 9-2. Integrated Treatability Schedule.

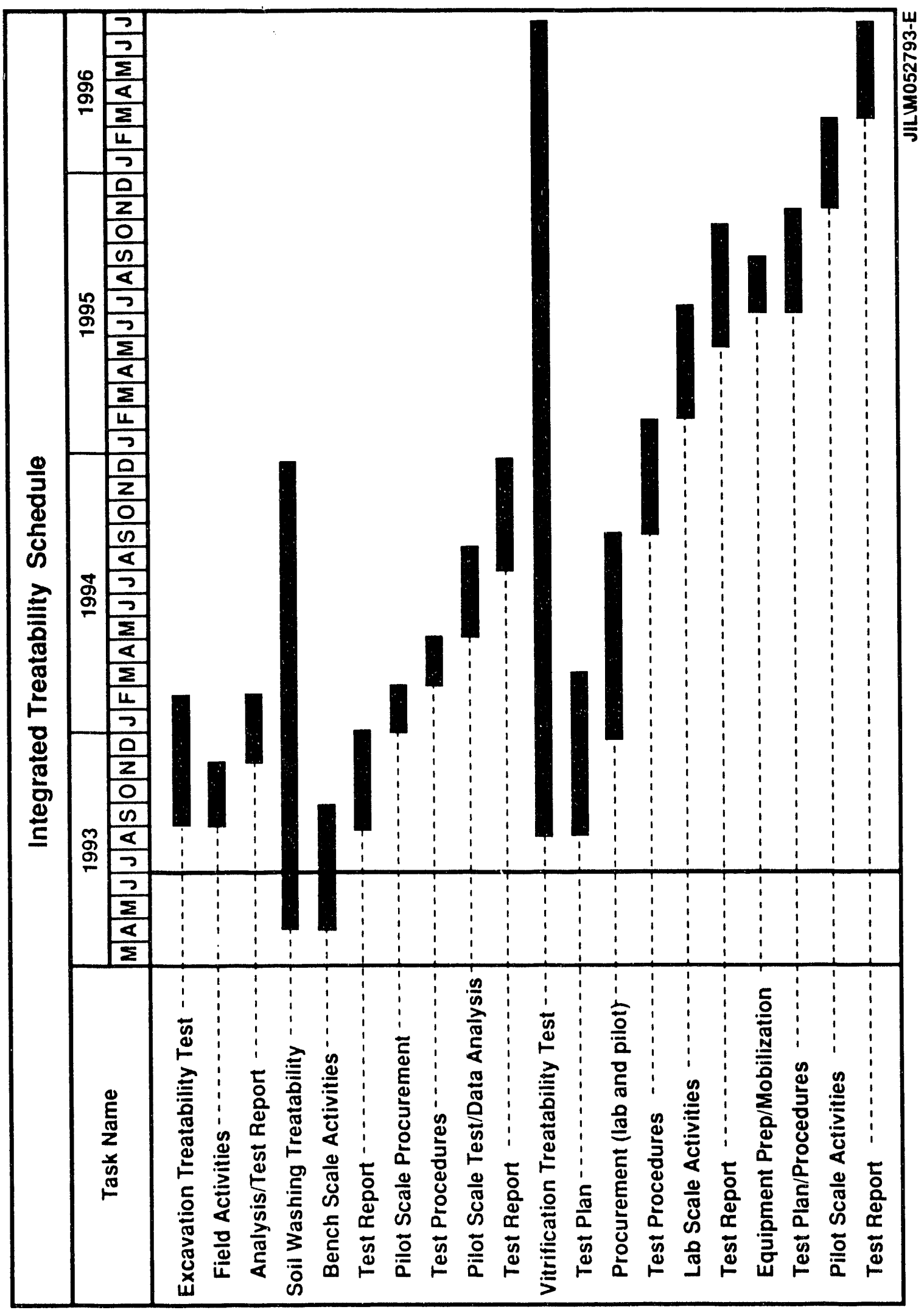


DOE/RL-93-04, Rev. 1

\subsection{PROGRAM ORGANIZATION}

The organization for performing tasks associated with the treatability test is shown graphically in Figure 10-1. WHC Environmental Restoration Engineering Function has direct responsibility for the planning, execution, and evaluation of the test. 
Figure 10-1. 100 Area Excavation Treatability

Test Program Organization.

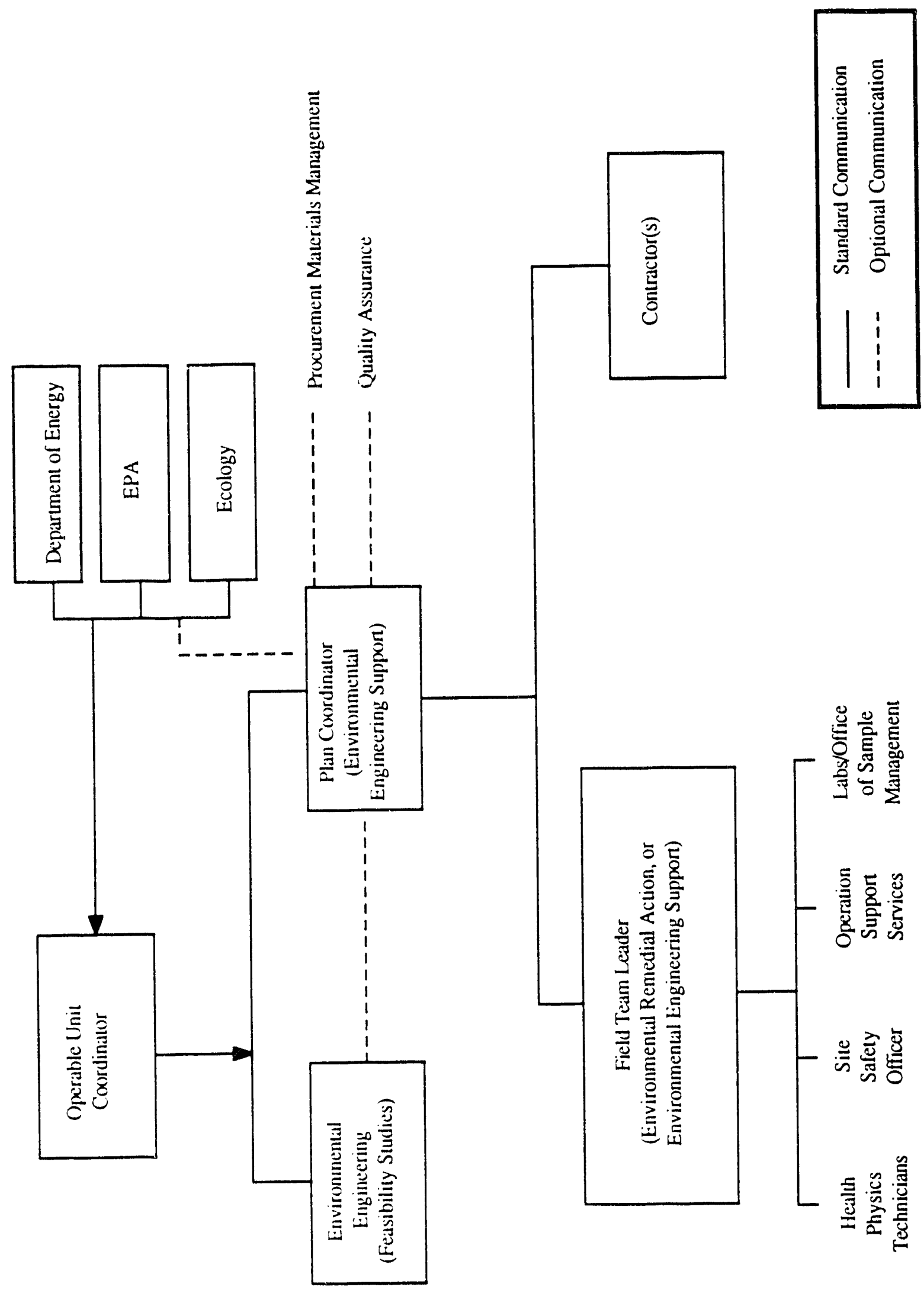




\subsection{REFERENCES}

Bigu, J. and M. G. Grenier, 1989. "Reduction of Airborne Radioactive Dust by Means of a Charged Water Spray," American Industrial Hygiene Association Journal, Volume 50, Number 7, pages 336 - 345, July 1989.

Cowherd, C., P. Englehart, G. E. Muleski, J. S. Kinsey, and K. D. Rosbury, 1990, Control of Fugitive and Hazardous Dusts, Pollution Technology Review No. 192, Midwest Research Institute. Kansas City, Missouri and PEI Associates, Inc., Golden, Colorado.

Dixon, W. J. and F. J. Massey Jr., 1969, Introduction to Statistical Analysis, McGraw-Hill Book Company, New York, 1969.

DOE-RL, 1992a, Engineering Evaluation of the 618-9 Burial Ground Expedited Response Action, DOE/RL-91-38, January 1992, U.S. Department of Energy, Richland Operations Office, Richland, Washington.

DOE-RL, 1992b, Expedited Response Action Assessment for 316-5 Process Trenches, DOE/RL-92-32, Rev. 0, July 1992, U.S. Department of Energy, Richland Operations Office, Richland, Washington.

DOE-RL, 1992c, 100 Area Feasibility Study Phases 1 and 2, DOE/RL-92-11, Draft A, July, 1992, U.S. Department of Energy. Richland Operations Office, Richland, Washington.

DOE-RL, 1992d, Remedial Investigation/Feasibility Study Work Plan for the 100-FR-I Operable Unit. Hanford Site, Richland, Washington. DOE/RL-90-33, Rev. 0, April 1992, U.S. Department of Energy. Richland Operations Office, Richland, Washington.

DOE-RL, 1992e, RCRA Facility Investigation/Corrective Measures Study Work Plan for the 100-HR-I Operable Unit, Hanford Site, Richland, Washington, DOE/RL-88-35, Rev. 0, September 1992. U.S. Department of Energy, Richland Operations Office. Richland, Washington.

DOE-RL, 1992f, Treatability Study Program Plan, DOE/RL-92-48, Draft A, 1992, U.S. Department of Energy, Richland Operations Office, Richland, Washington.

Duce, S. W., J. Low, P. G. Shaw, G. K. Becker, G. G. Loomis, 1988, Contamination Control Techniques for Retrieval of Buried TRU Waste. EGG-PHY-8209 Volume 1. Idaho National Engineering Laboratory, Idaho Falls, Idaho.

Duce, S. W., M. R. Winberg, and A. L. Freeman, 1989. Basic Radiological Studies Contamination Control Experiments. EFF-WM-8724, Idaho National Engineering Laboratory, Idaho Falls, Idaho. 
Dorian, J. J. and V. R. Richards, 1978, Radiological Characterization of the Retired 100 Areas, UNI-946, United Nuclear Industries, Inc., Richland, Washington.

Ecology, EPA, and DOE, 1989 et seq., Hanford Federal Facility Agreement and Consent Order, 2 vols., as amended, Washington Department of Ecology, U.S. Environmental Protection Agency, and U.S. Department of Energy, Olympia, Washington.

EPA, 1979, Iron and Steel Plan Open Dust Source Fugitive Emission Evaluation, EPA/600/2-79-103, U.S. Environmental Protection Agency, Washington, D.C.

EPA, 1985, Dust Control at Hazardous Waste Sites, EPA/540/2-85/003, U.S. Environmental Protection Agency, Washington, D.C.

EPA, 1987, Data Quality Objectives for Remedial Response Activities, Development Process, EPA/540/G-87/003, U.S. Environmental Protection Agency, Washington, D.C.

EPA, 1988, Compilation of Air Pollutant Emission Factors, EPA-AP42, 2 Vol., U.S. Environmental Protection Agency, Washington, D.C.

EPA, 1989, Guide for Conducting Treatability Studies Under CERCLA, EPA/540/2-89/058, U.S. Environmental Protection Agency, Washington, D.C.

McCoy, J. F., W. E. Schroeder, S. R. Rajan, S. K. Ruggieri, and F. N. Kissell, 1985, "New Laboratory Measurement Method for Water Spray Dust Control Effectiveness," American Industrial Hygiene Association Journal, Vol 46, No. 12, pp 735 - 740, December 1985.

Page, S. J. and J. C. Volkwein, 1986, "Foams for Dust Control," Engineering and Mining Journal, Vol 187, pp 50 - 54.

Rosbury, K. D., 1985, Handbook of Dust Control at Hazardous Waste Sites, EPA/540/2-85/003, U.S. Environmental Protection Agency, Washington, D.C.

Termine, F. and J. R. Favilla, 1987, "Chemical Methods Reduce Fugitive Dust," Power Engineering, Vol 91, pp 26 - 29, January 1987.

UNI, 1987, Radionuclide Inventory and Source Terms for the Surplus Production Reactors at Hanford, UNI-3714, Revision 1, April 1, 1987, United Nuclear Corporation, Richland, Washington.

WAC 173-360, 1993, "Minimum Standards for Construction and Maintenance of Wells", Washington Administrative Code, as ammended.

WHC, 1988, Environmental Compliance Manual, WHC-CM-7-5, Westinghouse Hanford Company, Richland, Washington. 
WH'_, 1990, Environmental Engineering, Technology, and Permitting Function Quality Assurance Program Plan, WHC-EP-0383, December 1990, Westinghouse Hanford Company, Richland, Washington.

WHC, 1992, Hanford Site Weather Enclosures 100 B/C Area Final Value Engineering Study Report, WHC-SD-EN-ES-026, Rev. 0, prepared by Los Alamos Technical Associates, Inc., Los Alamos, New Mexico, for Westinghouse Hanford Company, Richland, Washington.

Winberg, M. R. and V. E. Wixom, 1992, Fugitive Dust Control Experiments Using Soil Fixatives on Vehicle Traffic Surfaces, EGG-WTD-10354, Idaho National Engineering Laboratory, Idaho Falls, Idaho. 
DOE/RL-93-04, Rev. I

APPENDIX A

SAMPLING AND ANALYSIS REQUIREMENTS 
DOE/RL-93-04, Rev. 1 


\section{CONTENTS}

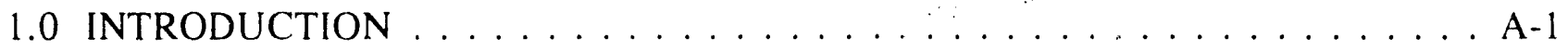

2.0 SAMPLING OBJECTIVES $\ldots \ldots \ldots \ldots \ldots \ldots \ldots \ldots$ A-1

2.1 FIELD/LABORATORY RADIONUCLIDE ANALYSIS CORRELATION . . A-1

2.2 DUST CONTROL $\ldots \ldots \ldots \ldots \ldots \ldots \ldots \ldots \ldots \ldots \ldots \ldots \ldots$

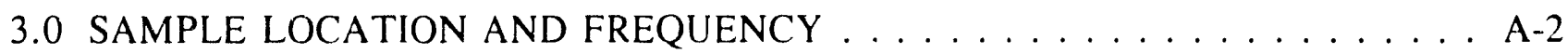

3.1 FIELD/LABORATORY RADIONUCLIDE ANALYCIS CORRELATION : A A-2

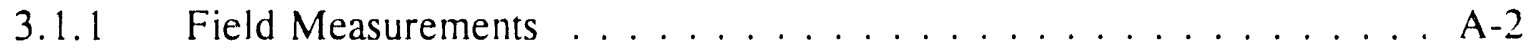

3.1 .2 Laboratory Analyses . . . . . . . . . . . . . A-2

3.2 DUST CONTROL . . . . . . . . . . . . . . . . . . A-5

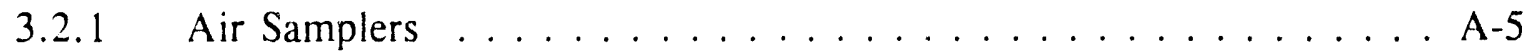

3.2 .2 Real Time Air Sampling $\ldots \ldots \ldots \ldots \ldots \ldots \ldots \ldots$ A 5

3.2.3 Personal Air Samplers . . . . . . . . . . . . . . . . . A.6

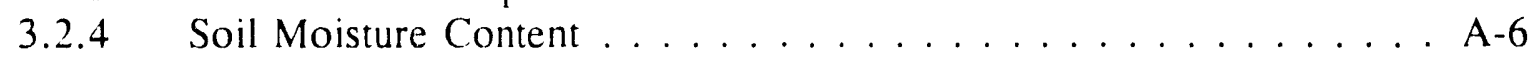

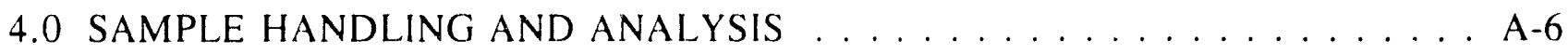

4.1 FIELD/LABORATORY RADIONUCLIDE ANALYSIS CORRELATION . . A-6

4.2 DUST CONTROL $\ldots \ldots \ldots \ldots \ldots \ldots \ldots \ldots \ldots \ldots$. . . . . . . . .

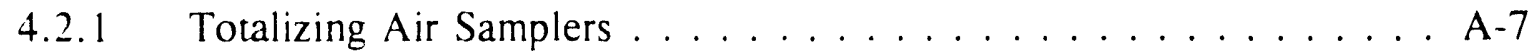

4.2.2 Real-Time Air Sampler . . . . . . . . . . . . . . A A-7

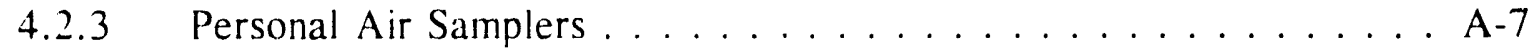

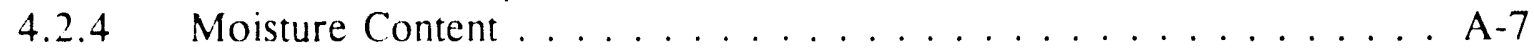

5.0 REFERENCES ....................... . . .

FIGURE:

A-1 Suggested Location of Field Measurement Samples $\ldots \ldots \ldots \ldots \ldots$ A $\ldots \ldots$

\section{TABLE:}

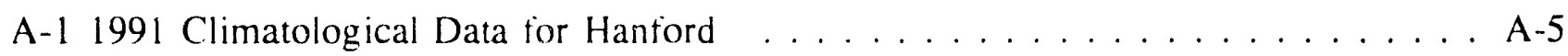




\subsection{INTRODUCTION}

This appendix discusses the requirements for obtaining and analyzing samples as part of the 100 Area excavation treatability test. A successful treatability test requires sampling and analysis to achieve representative characterization of the soils for the field/laboratory radionuclide analysis correlation and for determination of the amount of airborne dust generated by the excavation operations. The scope includes sampling and analysis for both the remedy selection and remedy design phases of treatability testing.

This appendix specifies the general sampling and analysis requirements for conducting the excavation treatability study. The test contractor will document specific sampling and analysis details in test procedures or other documents based upon the requirements stated in this appendix.

\subsection{SAMPLING OBJECTIVES}

\subsection{FIELD/LABORATORY RADIONUCLIDE ANALYSIS CORRELATION}

Sampling objectives for the field/laboratory radionuclide analysis correlation are:

- obtain representative measurements and samples of the soil in the test site

- determine in situ soil radionuclide concentrations

- derive a correlation between field measurements and analyses performed in fixed laboratories.

\subsection{DUST CONTROL}

Sampling objectives for the dust control test are.

- obtain representative samples of airborne particulates in and around the excavation site

- determine concentrations of airborne particulates. 


\subsection{SAMPLE LOCATION AND FREQUENCY}

\subsection{FIELD/LABORATORY RADIONUCLIDE ANALYSIS CORRELATION}

\subsubsection{Field Measurements}

3.1.1.1 Required Number of Samples - The number of samples required to statistically estimate the mean concentration at each depth of measurement can be obtained from equation 1 (Dixon and Massey 1969):

$$
N=\left(\frac{z \sigma}{d}\right)^{2}
$$

where $\mathrm{N}$ is number of samples, $\mathrm{z}$ is normal standard deviate, sigma is standard deviation, and $d$ is interval or precision of the estimate. Using this equation, 16 samples per excavation lift are required to meet the statistical requirements, noting that the normal standard deviation at $95 \%$ confidence is 1.96 , and assuming the following:

- mean concentration is known within $0.5 \mathrm{pCi} / \mathrm{g}$

- background has a standard deviation of $1 \mathrm{pCi} / \mathrm{g}$.

3.1.1.2 Sample Location - Samples will be taken along two sets of perpendicular centerlines as shown in Figure A-1. Thirteen samples will be taken at the points indicated, starting at the center and moving out north, south, east, and west in 3 -ft increments. The remaining three samples will be collected, at the field team leader's discretion, at three of the four diagonal locations indicated on Figure A-1. If contamination is found to extend beyond the confines of the original crib, these diagonal sample points will be moved out to the approximate radius of contamination. Additionally, the discretionary samples may be used to sample areas with local changes in soil type or other anomalies.

\subsubsection{Laboratory Analyses}

3.1.2.1 Required Number of Samples - The in situ radiation measurements for each type of detector and technique, within the range of $1 / 3$ to 3 times the performance level, will be regressed against the radionuclide concentrations, as determined by the laboratory analyses of soil samples. The regression will result in a relationship between in situ counts per minute and soil concentrations ( $\mathrm{pC} . \mathrm{i} / \mathrm{g}$ ). The number of samples necessary to achieve a $95 \%$ confidence estimation of the relationship can be determined from equation 2 (Dixon and Másscy 1969): 
DOE/RL-93-04, Rev. 1

Figure A-1. Suggested Field of Measurement Samples.

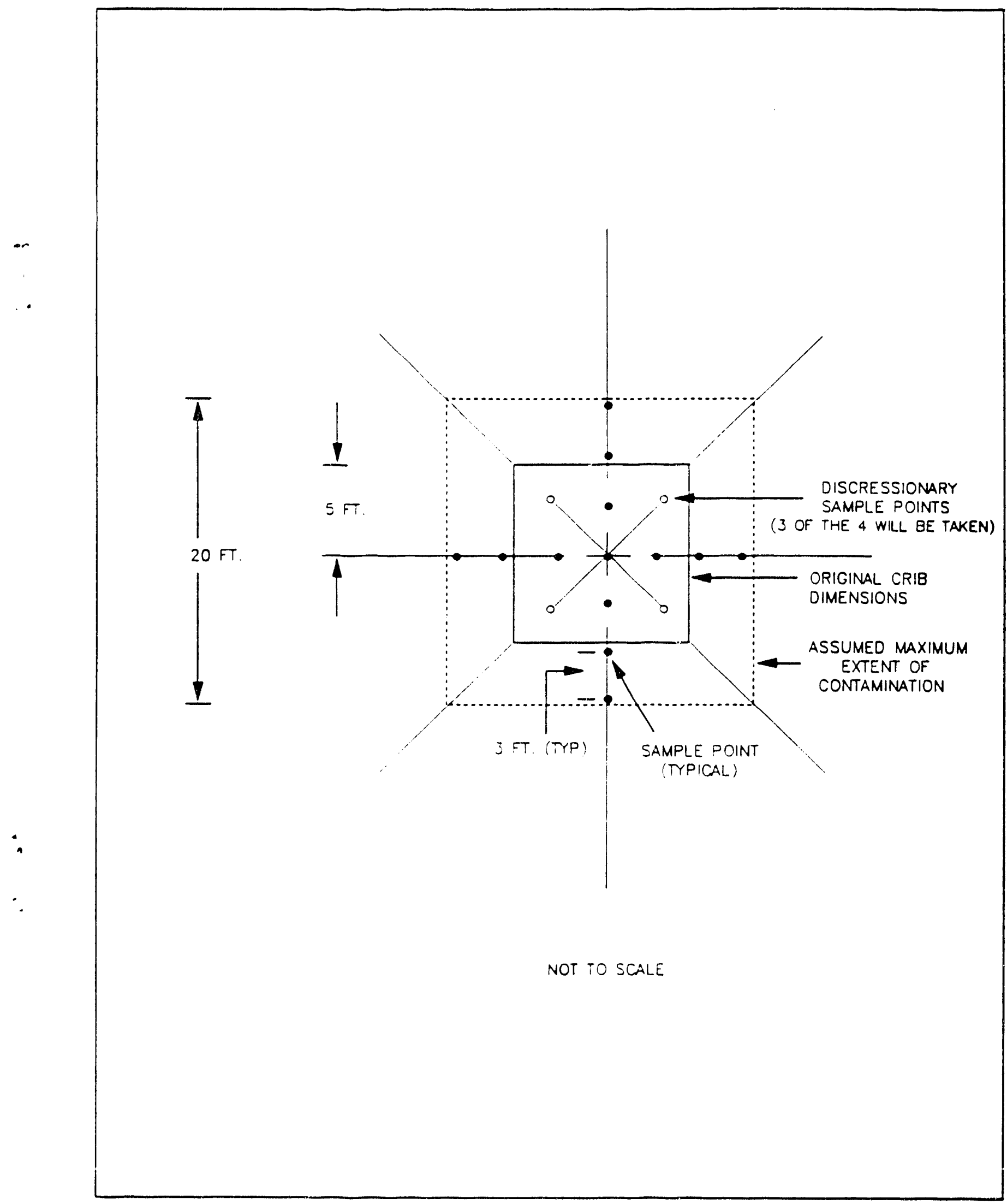




$$
d=t \sigma_{y} \sqrt{\frac{1}{N}+\frac{(\Delta X)^{2}}{(N-1) \sigma_{x}^{2}}}
$$

d difference from the expected value

For equation 2, the variables are defined as:

$t \quad \mathrm{~N}-2$ degrees of freedom $t$ deviate for $95 \%$ confidence

$\sigma_{\mathrm{y}}$ fractional coefficient of variation of the soil concentration

$\sigma_{x}$ fractional coefficient of variation of the in situ measurement

$\mathrm{N}$ number of samples required

$\Delta \mathrm{X}$ fractional difference between field measurement and actual levels that represent a measurable difference in soil concentration.

As with the in situ measurements, the goal is to collect sufficient samples so that the soil concentration can be predicted within $0.5 \mathrm{pCi} / \mathrm{g}(\mathrm{d}=0.5 \mathrm{pCi} / \mathrm{g})$; however equation 2 cannot be explicitly solved for $\mathrm{N}$. Therefore, assuming:

$$
\begin{aligned}
& \mathrm{N}=20 \\
& \mathrm{t}=2.101 \text { (the } \mathrm{t} \text { score for two-sided distribution, at } \mathrm{N}-2=18 \text { ) } \\
& \sigma_{y} \quad=0.2 \text { (20\% uncertainty from laboratory analyses) } \\
& \sigma_{x}=0.1(10 \% \text { uncertainty from field measurements [conservative estimate } \\
& \text { of field estimate capabilities|) } \\
& \Delta \mathrm{X}=0.1 \text { (Can measure a } 10 \% \text { change in soil radionuclide concentrations) }
\end{aligned}
$$

The difference from the expected value $(\mathrm{d})$ is $0.13 \mathrm{pCi} / \mathrm{g}$. While this indicates that fewer than 20 samples are required to supply the necessary regression between field measurements and laboratory samples, it is recommended that at least 20 of the field sample points are compared with laboratory analysis. Equation 2 does not account for variations in soil moisture content, therefore the 20 sample points chosen for analysis must all have essentially the same moisture content. To determine the effect of soil moisture on the correlation, another 20 samples are selected with moisture contents covering the desired range. These samples are also sent to the laboratory for analysis. The results are compared to the expected results, based on the field data, and correla-tions determined for the different moisture contents. Using this approach, a total of 40 samples are analyzed in the laboratory, 20 for the base correlation and 20 more for the variability of the correlation with moisture content.

3.1.2.2 Sample Location - Samples taken to the laboratory for analysis will be randomly selected from all field measurement locations from all lifts (a total of approximately 192 samples). 


\subsection{DUST CONTROL}

The number of samples necessary to achieve a given level of confidence can be obtained from Equation 1. For $95 \%$ confidence $(z=1.96)$ and a relative error in the measurement of $20 \%(\sigma)$, the dust concentration can be estimated to $10 \%(\mathrm{~d})$ with 16 samples.

\subsubsection{Air Samplers}

The primary source of error for air samplers is determining the amount of time they are within the dust plume. The air samplers will, at minimum, be placed both upwind and down wind of the site. To maximize the time within the dust plume, the samplers are placed based on average wind direction and times obtained from the onsite meteorological station. This information will also be used to estimate the fraction of the plume intercepted by each sampler.

The locations of the air samplers will be adjusted in the field based on the current wind direction data collected from the meteorological station. In general, prevailing winds are from the northwest throughout the year, and secondary maxima are indicated for southwesterly winds. Winds from the northwest quadrant occur most often during the summer and winter. During the spring and fall, the frequency of southwesterly winds increases. It is expected that the test excavation program will be conducted in September and/or October. Table A-1 lists the climatological data available from the Hanford Meteorology Station for 1991, measured on a tower $50 \mathrm{ft}$ above the ground.

Table A-1. 1991 Climatological Data or Hanford.

\begin{tabular}{|c|c|c|c|}
\hline Month & $\begin{array}{c}\text { Average Wind Speed } \\
(\mathbf{m p h})\end{array}$ & $\begin{array}{c}\text { Peak Wind Speed } \\
(\mathbf{m p h})\end{array}$ & $\begin{array}{c}\text { Peak Gust Direction } \\
\text { (wind from the:) }\end{array}$ \\
\hline September & 7.1 & 42.9 & West-rnorthwest \\
\hline October & 6.7 & 54.7 & West-southwest \\
\hline
\end{tabular}

Source: DOE-RL, 1991, Remedial Investigation/Feasibility Study Work Plan for the 100-BC-1 Operable Unit, Hanford Site, Richland, Washington. DOE/RL-90-07. Draft A. U.S. Department of Energy, Richland Operations Office, Richland. Wahsington.

\subsubsection{Real-Time Air Sampling}

The real-time total dust air samples are taken up and downwind of each dust- producing activity. At least 16 locations will be sampled every $2 \mathrm{hr}$. The samples are taken so they form a circuit around the excavation. Prior to the start of the sampling circuit, the current wind direction is determined. The locations of the actual samples will be determined by the sample technician so that the samples are obtained both upwind and downwind of the area/dust source of interest. The upwind points are important to determine the amount of dust entering the site. In order to accurately record the reading locations, a standard site 
map showing the excavation and associated units and the actual monitoring locations is completed for each sampling circuit. Real-time air samples will not be obtained in the excavation, but will be located around the per; ,eter of the excavation.

A second program of real-time air sampling is performed at the completion of the work day, as the test plan describes. Real-time dust measurements are taken $1 \mathrm{hr}$ after all dust suppression measures have been completed for the work day. A second set of real-time dust measurements will be obtained $2 \mathrm{hr}$ after the end of the work day, and a third set of realtime dust measurements will be obtained $3 \mathrm{hr}$ after the end of the work day. This second program provides the data for the crusting agent dust control tests.

\subsubsection{Personal Air Samplers}

Personal air samplers for total dust monitoring are worn by the backhoe operators and the sample and ground technicians working in the exclusion zone. New filters are installed at the start of each work day and collected at the end of the work day.

\subsubsection{Soil Moisture Content}

Soil moisture content samples are taken from points in the excavation and clean soil stockpile. Moisture content samples are obtained in the Phase 1 testing to assess the natural moisture content of the soil, and samples are obtained following the excavation of each lift. A total of 10 moisture content samples are obtained per lift in the excavation and two samples per lift from the material placed in the stockpile area. During the Phase 2 and 3 testing programs, soil moisture content samples are obtained for each lift, after the application of dust suppression measures.

\subsection{SAMPLE HANDLING AND ANALYSIS}

\subsection{FIELD/LABORATORY RADIONUCLIDE ANALYSIS CORRELATION}

Soil samples will be collected from each sample point (Figure A-1 shows a suggested sample layout), placed in a sample container. marked, and labelled as required. Those samples for laboratory analysis are shipped to the appropriate laboratory. 


\subsection{DUST CONTROL}

\subsubsection{Totalizing Air Samplers}

The exposed filters are collected at the end of the work day and prior to the start of the next work day, labeled, and transported to the analytical laboratory. Immediately following collection, the filters are screened for radiation using the field screening equipment.

\subsubsection{Real-Time Air Sampler}

Real-time air monitoring will be performed according to the manufacturer's directions for use, and the results are noted on the sample log for correlation with the field activity logs and other data.

\subsubsection{Personal Air Samplers}

The exposed filters are collected at the end of the work day, labeled, and transported to the analytical laboratory. Immediately following collection, the filters are screened for radiation using the field screening equipment.

\subsubsection{Moisture Content}

Following collection in the field, the soil moisture content samples are logged, labelled, and transferred to the testing facilities for analysis. Original sample material not used in testing will be archived in the field until the completion of the excavation, in the event that a confirmation of the test result is required.

\subsection{REFERENCE}

Dixon, W. J. and F. J. Massey Jr., 1969, "Introduction to Statistical Analysis," McGrawHill Book Company, New York, 1969. 
DOE/RL-93-04, Rev. 1

\section{DISTRIBUTION}

\section{Number of Copies}

\section{Onsite}

31

U.S. Department of Energy, Richland Field Office

J.K. Erickson (3)

A5-19

Public Reading Room

A 1-65

1

Pacific Northwest Laboratory

Hanford Technical Library

P8-55

48

Westinghouse Hanford Company

L.D. Arnold

B2-35

EDMC (9)

H6-08

ERC (G. Fitzgibbon)

H6-07

ERE (F. Stone) (2)

H6-01

ERE Project File

H6-03

ER Program Office (2)

H6-27

J.M. Frain (28)

H6-04

IRA (3)

H4- 17

Resource Center

N3-05 

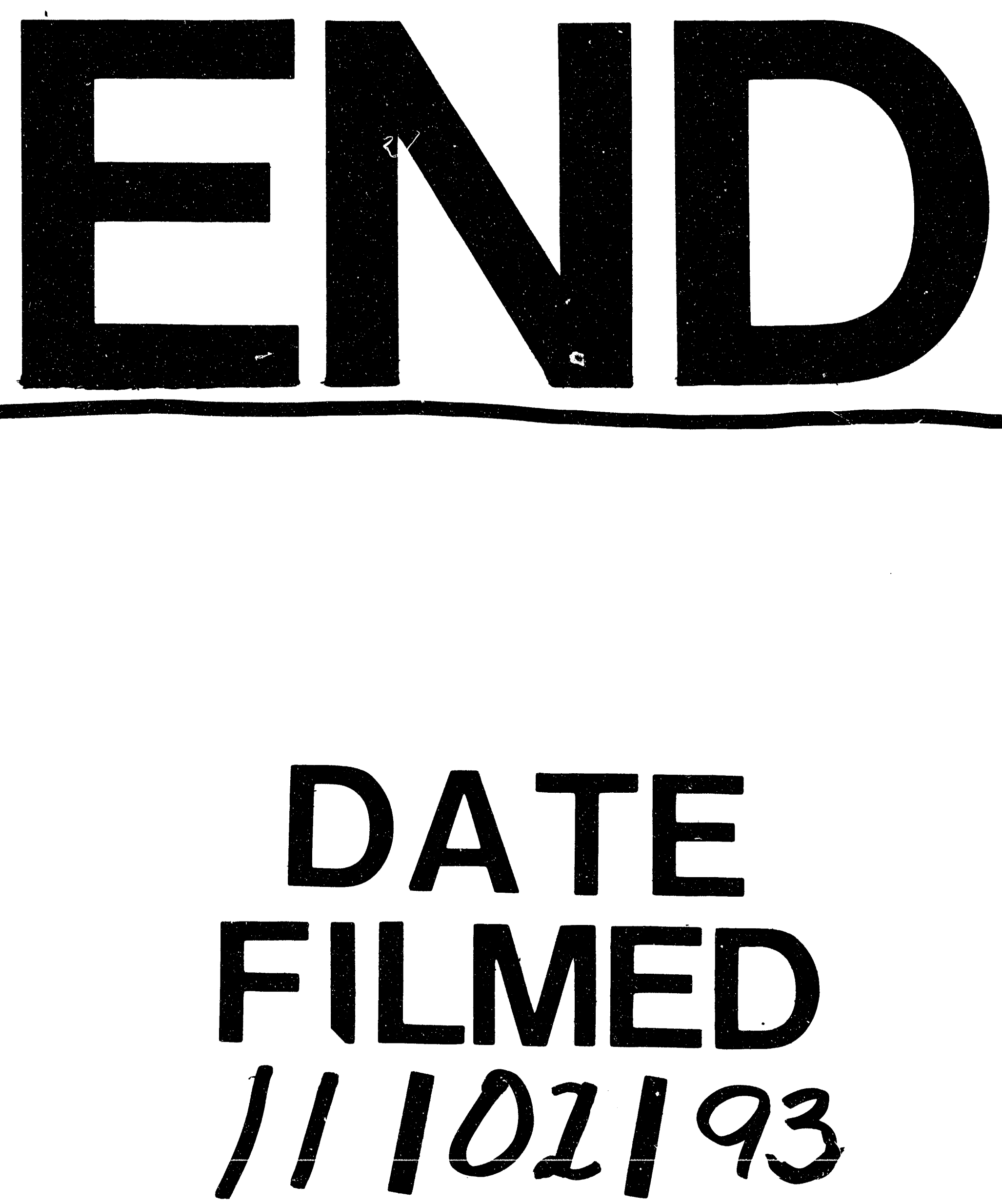
